Research article

\title{
Neuroservice proconvulsive (NS-PC) set: A new platform of electrophysiology-based assays to determine the proconvulsive potential of lead compounds
}

\author{
Esther Steidl $^{\mathrm{a}, *}$, Melanie Gleyzes ${ }^{\mathrm{a}}$, Fabien Maddalena $^{\mathrm{a}}$, Dominique Debanne ${ }^{\mathrm{b}}$, Bruno Buisson ${ }^{\mathrm{a}}$ \\ ${ }^{a}$ Neuroservice SARL, 595 rue Pierre Berthier, 13593 Aix-en-Provence, France \\ ${ }^{\mathrm{b}}$ UNIS, UMR1072 INSERM - Aix-Marseille Université, 53 Bvd Pierre Dramard, 13015 Marseille, France
}

\section{A R T I C L E I N F O}

\section{Keywords:}

Seizure liability

Proconvulsive

Safety pharmacology

Hippocampal slices

Multielectrode arrays

Extracellular recording

Methods

\begin{abstract}
A B S T R A C T
Introduction: Failures in drug development often result from the emergence of unexpected adverse drug reactions. It is clear that adverse drug reactions, including seizure liability, should be assessed earlier. The goal of the present work was to develop a new platform of in vitro assays, NS-PC set (for Neuroservice proconvulsive set), to determine the proconvulsive potential of compounds earlier in preclinical development.

Methods: Assays were based on electrophysiological recordings in acute hippocampal slices performed with multielectrode arrays. 4 reference proconvulsive/seizurogenic compounds (4-aminopyridine, bicuculline, kainate and carbachol) and 4 anti-epileptic drugs (AEDs; phenobarbital, carbamazepine, clonazepam and valproic acid) were evaluated on electrophysiological endpoints involved in seizure risk (neuronal excitability, balance of excitatory/inhibitory synaptic transmission, occurrence of neuronal synchronization mechanisms materialized by epileptiform discharges).

Results: The reference compounds increased the number and area under the curve of population spikes, triggered epileptiform discharges and enhanced the firing rate of CA1 neurons. The effects of the 4 antiepileptic drugs were assessed on these 3 parameters. They were able to partially of completely reverse the effects of proconvulsive compounds.

Discussion: The use of reference proconvulsive compounds and AEDs validated the electrophysiological parameters to detect proconvulsive risk. Systematic evaluation of compounds with the 3 complementary endpoints increase the probability to detect seizure liability in vitro. Depending on the compound mechanism of action, only one or two of the identified parameters might be modified.
\end{abstract}

\section{Introduction}

Drug development is a long and challenging process. Despite soaring research and development costs, the number of approved drugs have failed to increase and remains around 15-30 new drug approved yearly (Kaitin, 2010). Only 11\% of drugs that enter clinical trials are approved by the regulatory agencies. Behind the lack of efficacy, the second cause of failure in clinical trials (about 30\%) is the emergence of unexpected adverse drug reaction or toxicity of the developed drug (Kola \& Landis, 2004). Among safety issues, the occurrence of seizure(s) or proconvulsive effects are among the most dreaded, as they often result in the termination of the project, especially if they are discovered late in the development phases. Seizure liability is more likely to occur for central nervous system (CNS) compounds but also occurs for compounds developed for other therapy areas, such as infections, cardiovascular or respiratory areas (Easter et al., 2009). The proconvulsive potential of pharmacological compounds was classically evaluated quite late into the drug development process, at the end of the preclinical phases. It was evaluated along behavioral and physiological observations such as Irwin test or the functional observation battery (FOB) test, that are a part of regulatory safety assay, mandatory before clinical trials (Andrade et al., 2016; Irwin, 1968; Moser, Cheek, \&

\footnotetext{
Abbreviations: 4-AP, 4-aminopyridine; aCSF, Artificial cerebrospinal fluid; AED, Anti-epileptic drug; AUC, Area under the curve; CNS, Central nervous system; DG,

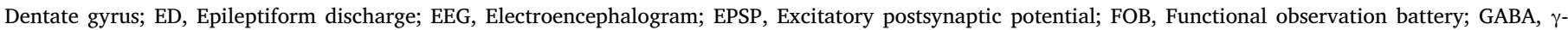

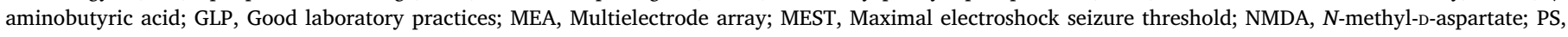
Population spike; PTZ, Pentylenetetrazole; R\&D, Research and Development

* Corresponding author at: Neuroservice, Domaine de Saint Hilaire, 595 rue Pierre Berthier, CS 30531, 13593, Aix en Provence cedex 03, France.

E-mail address: esther.steidl@neuroservice.com (E. Steidl).
} 
MacPhail, 1995). However, retrospective analysis of clinical and preclinical data from 141 molecules from 5 different pharmaceutical companies highlighted that Irwin test and FOB poorly predicted CNS adverse effect most commonly observed in clinical phase I (Mead et al., 2016). Even in pre-clinical phases, compounds that fail due to proconvulsive activity have already cost millions of dollars (DiMasi, Grabowski, \& Hansen, 2016). With the aim to de-risk drug development, it is widely accepted that seizure liability should be assessed earlier in drug development processes (Bradley, Luithardt, Metea, \& Strock, 2018; Easter et al., 2009; Easter, Sharp, Valentin, \& Pollard, 2007; Hamdam et al., 2013; Zhang et al., 2011). Unlike cardiac safety, there are no guidelines from regulatory agencies about the most appropriate assays to detect seizure liability in pre-clinical phases and to mitigate this risk (FDA, 2017).

Different assays already exist to evaluate the proconvulsive potential of compounds, however, there is no consensus on which should be employed. Drug seizure liability can be assessed in rodent assays such as the penthylenetetrazole (PTZ) assay (Löscher, 2009; Löscher \& Schmidt, 1988), electroconvulsive shock threshold (MEST) assay (Bankstahl, Bankstahl, Bloms-Funke, \& Löscher, 2012; Kitano, Usui, Takasuna, Hirohashi, \& Nomura, 1996; Löscher, Hönack, Fassbender, \& Nolting, 1991) and electroencephalogram (EEG) (Dürmüller, Guillaume, Lacroix, Porsolt, \& Moser, 2007; Pillai \& Sperling, 2006), although not necessarily conducted under good laboratory practices (GLPs) (Authier et al., 2016). Current in vitro techniques to detect seizure liability include the hippocampal brain slice assay (Easter et al., 2007; Accardi, Huang, \& Authier, 2018). Other assays such as the measure of the locomotor activity of zebrafishes (Winter et al., 2008) and electrophysiology on cultured cortical neurons (Bradley et al., 2018) are also documented, although less frequently used (Easter et al., 2007; Hamdam et al., 2013). An alternative to these in vivo or in vitro assays are in silico assays that could be used to predict the proconvulsive profiles of compounds without using animals (Zhang et al., 2011). However, none of these assays is ideal, each displaying different limitations (involving animal suffering, displaying a low throughput, a limited predictability, or results complex to interpret, not applicable for early development stages, etc).

It is desirable to establish and validate an assay to assess seizure liability in vitro that can be performed early in the drug development process, with the aim of reducing the cost of developing new drugs. Also, this assay should detect both seizurogenic compounds (compounds triggering overt motor convulsions) and proconvulsive compounds (compounds decreasing the threshold necessary to induce these convulsions or facilitating seizures). Depending on the benefit/risk ratio, a weak proconvulsive compound might be further developed, whereas if the compound is seizurogenic, its development will likely be terminated. In addition, it would be desirable for the assay to investigate the mechanism of action responsible for seizure liability.

In the present study, electrophysiological recordings in rodent brain slices were used to 1 - determine whether reference proconvulsive compounds increased neuronal excitability and 2- determine whether anti-epileptic drugs (AEDs) reversed the effects of proconvulsive compounds, and 3- describe a relationship between the parameters that are modified and the compound mechanism of action.

Electrophysiological parameters were recorded from rodent brain slices with multielectrode arrays (MEAs) that provide the multipoint recordings and are thus particularly suited to reveal synchronization occurring at the neuronal network level. Hippocampal slices were exposed to various reference proconvulsive or seizurogenic compounds (4-aminopyridine (4-AP), a $\mathrm{K}^{+}$channel blocker, bicuculline, a $\mathrm{GABA}_{\mathrm{A}}$ receptors antagonist, kainate, a ionotropic glutamate receptor agonist, and carbachol, a wide spectrum acetylcholine receptors agonist) to investigate what electrophysiological parameters are modified in the presence of such compounds. In addition, the capability of 4 anti-epileptic drugs to reverse the effects of proconvulsive compounds was assessed to validate the relevance of the identified parameters.
We identified three major electrophysiological parameters that were modified in the presence of proconvulsive compounds: the population spike (PS) shape and area, the CA1 neuron firing rate and the frequency of spontaneous epileptiform discharges (EDs) which occurred synchronously over the hippocampal network. Depending on the compound mechanism of action, one or several of the three parameters were modified and anti-epileptic drugs were able to modify these parameters in an opposite manner.

\section{Material and methods}

\subsection{Hippocampal slices preparation}

Experiments were carried out with 3 to 5 week-old Sprague Dawley rats without gender distinction (from Elevage Janvier, France). Animals were housed and used in accordance to the French and European legislations for animal care. They were maintained in animal facilities with $12 \mathrm{~h} / 12 \mathrm{~h}$ light/dark cycle, $22 \pm 2{ }^{\circ} \mathrm{C}$ room temperature, with food and water ad libitum. On the day of slice recording rats were euthanized by fast decapitation, without anesthesia. The brain was quickly removed and soaked in ice-cold oxygenated $\left(95 \% \mathrm{O}_{2}, 5 \% \mathrm{CO}_{2}\right)$ buffer with the following composition: $\mathrm{KCl} 2, \mathrm{NaH}_{2} \mathrm{PO} 41.2, \mathrm{MgCl}_{2} 7, \mathrm{CaCl}_{2}$ 0.5, $\mathrm{NaHCO}_{3} 26$, glucose 11 and sucrose 250 (in mM; pH7.3 \pm 0.1 ; 280-310 mOsm). Transverse hippocampus slices were cut with a Macllwain tissue-chopper (Campden instrument, UK) at $400 \mu \mathrm{m}$ thickness for PS or ED recordings. Coronal hippocampus slices were cut with a vibratome (Leica VT1200S, Leica Biosystems, Germany) at $350 \mu \mathrm{m}$ thickness for CA1 neuron firing recording. The slices were then allowed to recover in a holding chamber for at least $1 \mathrm{~h}$ at room temperature $\left(22 \pm 2{ }^{\circ} \mathrm{C}\right.$ ) in oxygenated artificial cerebrospinal fluid (aCSF) of the following composition in mM: $\mathrm{NaCl} 126, \mathrm{KCl} 3.5, \mathrm{NaH}_{2} \mathrm{PO}_{4} 1.2, \mathrm{MgCl}_{2}$ 1.3, $\mathrm{CaCl}_{2} 2, \mathrm{NaHCO}_{3} 25$, and glucose 11 (pH 7.3 \pm 0.1; 280-310 mOsm), bubbled with carbogen $\left(95 \% \mathrm{O}_{2}, 5 \% \mathrm{CO}_{2}\right)$.

Hippocampus slices were used within $8 \mathrm{~h}$ after their preparation. No difference was observed between the effect of compounds on first versus last slices used, for the measured parameters.

\subsection{Multi-electrode array set-up}

All the data were recorded with a MEA set-up from MultiChannel Systems (Germany). Recordings were carried out with 3-dimensional MEAs (Qwane Biosystems, Switzerland) with electrodes spaced by $100 \mu \mathrm{m}$ (for PS and CA1 neuron firing recordings) or $200 \mu \mathrm{m}$ (for ED recording). The flow rate was $3 \mathrm{ml} / \mathrm{min}$ and the perfused medium was kept at $37^{\circ} \mathrm{C}$ both with a heated perfusion cannula and a heating element placed below the MEA. Data were sampled at $20 \mathrm{kHz}$ for PS and recording of CA1 neuron firing and at $5 \mathrm{kHz}$ for ED recording. For CA1 neuron firing recording, a high-pass 2nd order Butterworth filter $(>200 \mathrm{~Hz}$ ) was used to isolate action potentials. For ED recording, a low-pass filter $(<20 \mathrm{~Hz})$ was used to isolate field potentials.

\subsection{Electrophysiological recordings}

Recording of PS area and shape: The hippocampal slice was placed on the MEA (electrodes spaced $100 \mu \mathrm{m}$ ) and one electrode was chosen to stimulate Schaffer collateral pathway. Over the recording sessions, slices were continuously perfused with oxygenated aCSF described above. An Input/Output curve was performed to set the intensity of stimulation evoking PS in the stratum pyramidale (stimulation between 50 and $600 \mu \mathrm{A}$, by $50 \mu \mathrm{A}$ steps). The stimulus, consisted of a biphasic current pulse (negative for $60 \mu$ s and then positive for $60 \mu \mathrm{s}$ ), was set $100 \mu \mathrm{A}$ above the threshold intensity evoking PS, and applied every $30 \mathrm{~s}$ to trigger responses in the CA1 region. After a 20 -min control period, the proconvulsive compound ( $10 \mu \mathrm{M}$ bicuculline, $100 \mu \mathrm{M} 4-\mathrm{AP}, 300 \mathrm{nM}$ kainate or $3 \mu \mathrm{M}$ carbachol) was applied over a 40 -min period. For evaluating the AEDs, after a 20-min control period, $100 \mu \mathrm{M} 4$-AP was 
applied alone first for $20 \mathrm{~min}$ and next co-applied with the AED (500 $\mu \mathrm{M}$ phenobarbital, $100 \mu \mathrm{M}$ carbamazepine, $1 \mu \mathrm{M}$ clonazepam or $700 \mu \mathrm{M}$ valproic acid) for $60 \mathrm{~min}$.

Recording of EDs: The hippocampal slices was placed on the MEA (electrodes spaced by $200 \mu \mathrm{m}$ ), so that electrodes covered the dentate gyrus (DG), CA3 and CA1 regions. Over the recording sessions, slices were continuously perfused with oxygenated aCSF as described above. After a 10-min recording in control conditions to verify the absence of EDs, the proconvulsive compound $(10 \mu \mathrm{M}$ bicuculline, $50 \mu \mathrm{M}$ 4-AP, $10 \mu \mathrm{M}$ kainate or $10 \mu \mathrm{M}$ carbachol) was applied over a 70-min period, in the aCSF described above or in an aCSF containing $5 \mathrm{mM}\left[\mathrm{K}^{+}\right](\mathrm{NaCl}$ 124.5, $\mathrm{KCl} 5, \mathrm{NaH}_{2} \mathrm{PO}_{4} 1.2, \mathrm{MgCl}_{2} 1.3, \mathrm{CaCl}_{2} 2, \mathrm{NaHCO}_{3} 25$ and glucose 11 , in $\mathrm{mM}$ ). For evaluating the AEDs, after a 10-min control period, $50 \mu \mathrm{M}$ 4-AP was applied alone first for $30 \mathrm{~min}$ and next co-applied with the AED $(500 \mu \mathrm{M}$ phenobarbital, $100 \mu \mathrm{M}$ carbamazepine, $1 \mu \mathrm{M}$ clonazepam or $700 \mu \mathrm{M}$ valproic acid) for $40 \mathrm{~min}$.

CA1 neuron firing: The hippocampal slice was placed on the MEA (electrodes spaced by $100 \mu \mathrm{m}$ ). One line of electrodes was placed in the stratum pyramidale to record the CA1 neurons spontaneous activity. During CA1 neuron firing experiments, different aCSF were successively applied: aCSF $3.5 \mathrm{mM}\left[\mathrm{K}^{+}\right]\left(\mathrm{NaCl} 126, \mathrm{KCl} 3.5, \mathrm{NaH}_{2} \mathrm{PO}_{4} 1.2, \mathrm{MgCl}_{2}\right.$ 1.3, $\mathrm{CaCl}_{2} 2, \mathrm{NaHCO}_{3} 25$ and glucose 11 , in $\mathrm{mM}$ ), aCSF $7 \mathrm{mM}\left[\mathrm{K}^{+}\right]$ ( $\mathrm{NaCl} 122.5, \mathrm{KCl} 7, \mathrm{NaH}_{2} \mathrm{PO}_{4} 1.2, \mathrm{MgCl}_{2} 1.3, \mathrm{CaCl}_{2} 2, \mathrm{NaHCO}_{3} 25$ and glucose 11 , in $\mathrm{mM})$ and aCSF $10 \mathrm{mM}\left[\mathrm{K}^{+}\right](\mathrm{NaCl} 119.5, \mathrm{KCl} 10$, $\mathrm{NaH}_{2} \mathrm{PO}_{4} 1.2, \mathrm{MgCl}_{2}$ 1.3, $\mathrm{CaCl}_{2}$ 2, $\mathrm{NaHCO}_{3} 25$ and glucose 11, in mM). After a 10 -min period in aCSF containing $10 \mathrm{mM}\left[\mathrm{K}^{+}\right]$, firing activity was recorded in aCSF containing $3.5 \mathrm{mM}\left[\mathrm{K}^{+}\right]$for $10 \mathrm{~min}$ in absence of compound, followed by a 30 -min period in the presence of the compound tested $(10 \mu \mathrm{M}$ bicuculline, $50 \mu \mathrm{M}$ 4-AP, $1 \mu \mathrm{M}$ kainate, $3 \mu \mathrm{M}$ carbachol, $500 \mu \mathrm{M}$ phenobarbital, $100 \mu \mathrm{M}$ carbamazepine, $1 \mu \mathrm{M}$ clonazepam or $700 \mu \mathrm{M}$ valproic acid) or vehicle. Next firing activity was recorded in aCSF containing $7 \mathrm{mM}\left[\mathrm{K}^{+}\right]$for $30 \mathrm{~min}$, and finally in aCSF containing $10 \mathrm{mM}\left[\mathrm{K}^{+}\right]$for $30 \mathrm{~min}$, still in the presence of compound tested or vehicle.

\subsubsection{Data analysis}

PS area and shape: The PS area under the curve (AUC) (between 2 and $100 \mathrm{~ms}$ after the stimulus) was calculated for each electrode of each slice using Igor Pro 6.22 software. The duration of PS increased in the presence of proconvulsive compounds but without exceeding $100 \mathrm{~ms}$ for compounds tested. For normalization, each PS area was normalized to the mean-averaged area recorded over a 20-min control period, before compound application. The data from each electrode within a single slice were first averaged. Next data from each slice in the same experimental conditions were averaged. Normalized PS AUC was plotted as a function of time \pm SEM. The number of spikes generated by a single stimulation was determined visually by using clampfit 10.3 software to average consecutive raw traces (from the last five minutes of compound application). The possible additional spikes at the end of each compound(s) application period were monitored at all the recorded electrodes, averaged for each slice and presented for each experimental condition in bar graph format as mean \pm SEM. On average, about 4 electrodes per slice were used to monitor the compound effect on the PS area and the number of spikes. For evaluating AEDs, the number of additional spikes triggered by 4 -AP was considered as $100 \%$. The mean number of multiple spikes over the last five minutes of application of the reference AED was expressed as a function of 4-AP-induced additional spikes (between $t=35-40 \mathrm{~min}$ ) and presented in a bar graph \pm SEM.

EDs: The ED frequency and amplitude were monitored all along the experiments. The ED frequency and amplitude were averaged in $30 \mathrm{~s}$ bins from 9 electrodes in each hippocampal slice ( 3 in each hippocampal sub-field CA1, CA3 and DG). Data from each slice in equivalent experimental conditions were next averaged. The frequency of EDs (in $\mathrm{Hz}$ ) were expressed as a function of time ( \pm SEM). For evaluating AEDs, the ED rate at the end of 4-AP application alone (at $t=37.5-40 \mathrm{~min}$ ) was considered as $100 \%$, the percentage of inhibition of EDs was quantified over the last $2.5 \mathrm{~min}$ of AED application and presented in a bar graph \pm SEM.

CA1 neuron firing: The neuron firing rate (in $\mathrm{Hz}$ ) was normalized to 1 in regard to the one recorded over the initial 10-min control period. In average, about 7 electrodes per slice were used to monitor the compound effect on the CA1 neuron firing. The data from each electrode within a single slice were first averaged. Next data from each slice in the same experimental conditions were averaged. Normalized firing rate was plotted as a function of time \pm SEM. The effect of compounds was quantified over the last five minutes in each aCSF (at $t=45-50 \mathrm{~min}$ for $3.5 \mathrm{mM} \mathrm{K}^{+}$aCSF, at $t=75-80 \mathrm{~min}$ for $7 \mathrm{mM} \mathrm{K}^{+} \mathrm{aCSF}$ and $t=105-110 \mathrm{~min}$ for $10 \mathrm{mM} \mathrm{K}^{+} \mathrm{aCSF}$ ).

\subsubsection{Drugs}

4-AP and carbamazepine were purchased from Abcam (UK), bicuculline, carbachol, kainate, phenobarbital, clonazepam and valproic acid were from Sigma-Aldrich (France). 1000-fold concentrated stock solutions were prepared in DMSO or deionized water. Stock solution were then aliquoted and stored at $-20^{\circ} \mathrm{C}$ until use. The vehicle concentration was adjusted to be equal over the entirety of each recording session or equal to the one in control experiments recorded in parallel (without exceeding $0.3 \%$ for DMSO).

\subsection{Statistical analysis}

Data were tested for statistical significance with two-tailed Student's $t$-test for comparison before/after compound application (for evaluating AED's effect on ED) or with Mann-Whitney test for unpaired comparison (between control and compound-exposed slices, at equivalent time points). As recordings obtained from different electrode in a single hippocampal slice could not be considered as fully independent, the number of slices (and not the number of recorded electrodes) was considered as the number of samples for statistical analyses. In figure legends, $\mathrm{n}$ corresponds to the number of slices.

A critical $p$ value $p<.05$ was considered significant for the statistical tests used throughout the study. * corresponds to $p<.05$, ** to $p<.01, * * *$ to $p<.001, * * * *$ to $p<.0001$, ns to non-significant.

\section{Results}

\subsection{Bicuculline, 4-AP and kainate increase the PS area and trigger multiple} spikes in response to a single stimulation

In response to a single stimulation of Schaffer collaterals (axons from the CA3 pyramidal neurons), excitatory postsynaptic potentials (EPSPs) could be measured in the stratum radiatum of the CA1 region of rat hippocampal slices. EPSPs result from the depolarization of the baso-lateral dendrites of the post-synaptic CA1 neurons in response to glutamate release from the presynaptic terminals of CA3 neuron axons. CA3 neurons also stimulate GABAergic interneurons that synapse onto CA1 pyramidal neurons and hyperpolarize them by releasing GABA. When the depolarization of the CA1 neurons reaches a defined threshold, an action potential is generated at the somatic level, in the stratum pyramidale, and propagates along the axon of CA1 neurons (Andersen, Bliss, \& Skrede, 1971; Klausberger, 2009). After Schaffer collaterals stimulation, population of CA1 neurons that are activated simultaneously and fire an action potential in synchrony give rise to a single population spike (PS), while recorded extracellularly (Fig. 1A, black trace).

The PS area and shape remain stable over at least $2 \mathrm{~h}$ when the stimulation is applied at $0.033 \mathrm{~Hz}$. Both parameters were monitored before and after application of reference proconvulsive compounds: bicuculline, 4-AP, kainate and carbachol. Among the 4 compounds that 
(a)

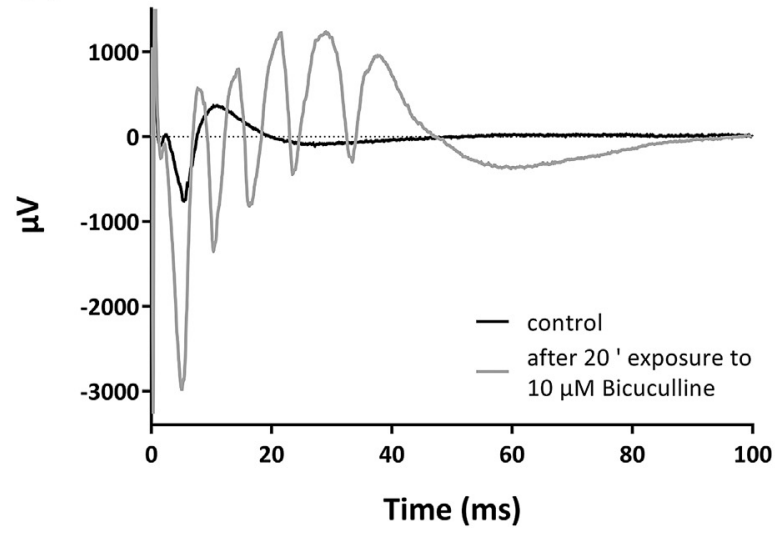

(b)

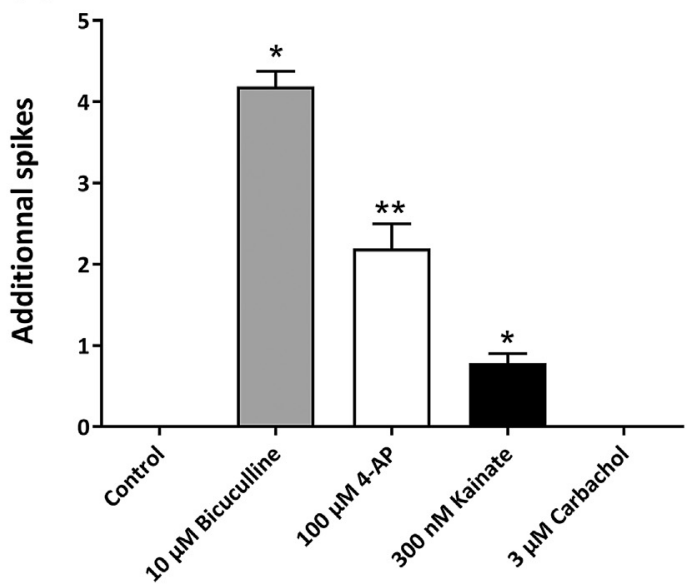

(c)

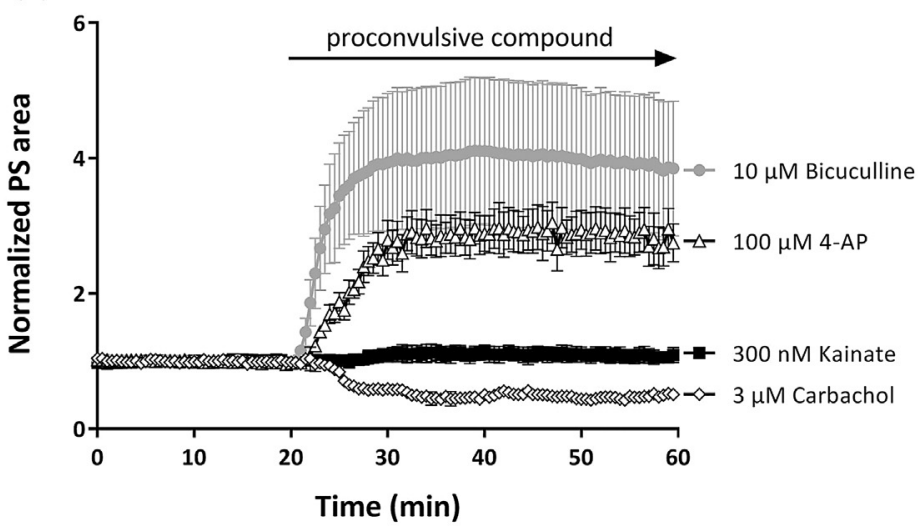

Fig. 1. Evaluation of bicuculline, 4-AP, kainate and carbachol on PS area and shape.

A: PS recorded from a representative electrode before (black trace) and 20 min after $20 \mu \mathrm{M}$ bicuculline application (grey trace).

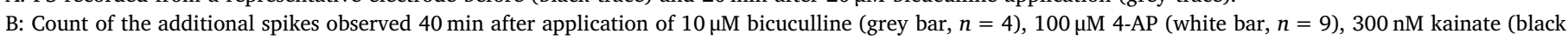

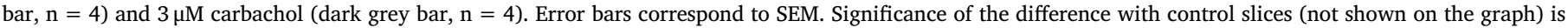
specified above bars $(*, p<.05 ; * *, p<.01$; Mann-Whitney test).

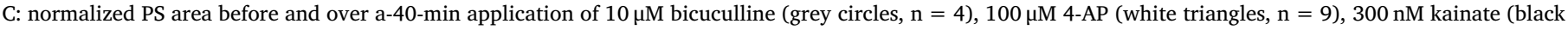
squares, $n=4$ ) and $3 \mu \mathrm{M}$ carbachol (white diamonds, $n=4$ ).

were evaluated, 3 increased the PS area (Fig. 1C) and the number of spikes generated in response to a single stimulation (Fig. 1B).

$10 \mu \mathrm{M}$ bicuculline $(n=4)$ rapidly and significantly increased the PS area $(p=.0286)$ and triggered multiples spikes (Fig. 1A: representative PS before, black trace, and after a 20-min bicuculline application, grey trace; the PS clearly display 4 additional spikes then). The PS area increased over the 10 first minutes of $10 \mu \mathrm{M}$ bicuculline application, and then remained quite steady until the end of the recording session. The PS area was then almost 4 times greater than in control conditions (the PS area was $3.85 \pm 1.00$, at endpoint). In parallel, the mean number of additional spikes was $4.2 \pm 0.2$ at endpoint, and significantly differed $(p=.0286)$ from the one in control experiments (no additional spikes in control conditions).

$100 \mu \mathrm{M}$ 4-AP $(n=9)$ also significantly increased the PS area (it was $2.75 \pm 0.28$ at endpoint; $p=.0061$ ) and triggered multiple spikes (the mean number of spikes was $2.2 \pm 0.3$ at endpoint, whereas no additional spikes were observed in control conditions, significant difference, $\mathrm{p}=.0061)$.

$300 \mathrm{nM}$ kainate $(n=4)$ did not increase the PS area $(p=.5714$; the PS area was $1.09 \pm 0.11$ at endpoint) but generated an additional spike (the mean number of additional spikes was $0.8 \pm 0.1$ at endpoint, whereas no additional spikes were observed in control conditions, significant difference, $\mathrm{p}=.0286$ ).

$3 \mu \mathrm{M}$ carbachol $(n=4)$ decreased the PS area, but this effect just failed to reach significance $(p=.0667)$. The PS area was $0.51 \pm 0.01$ at endpoint. Carbachol did not generate additional spikes, as in control experiments.

3.2. Phenobarbital, carbamazepine and clonazepam efficiently reversed 4$A P$-induced additional spikes but did not reverse 4-AP-induced increase of the PS area

The effects of four AEDs, phenobarbital, carbamazepine, clonazepam and valproic acid, were evaluated on PS recorded in the presence of $100 \mu \mathrm{M}$ 4-AP. As previously observed, 4-AP increased the PS amplitude and triggered two additional spikes on average (Fig. 2A: representative PS before, black trace, and 20 min after 4-AP application, dotted black trace). None of the evaluated AEDs significantly reversed the 4-AP effect on PS area (the PS area was $2.41 \pm 0.38,2.00 \pm 0.31$, $2.60 \pm 0.2$., $2.05 \pm 0.27$ after a 40-min co-application of 4-AP and phenobarbital $(n=3)$, carbamazepine $(n=3)$, clonazepam $(n=4)$ and valproic acid $(n=3)$, respectively, versus $2.74 \pm 0.20$ in hippocampal slices exposed to 4-AP only $(n=6)$, all at endpoint, Fig. 2B). Interestingly, three out of the four evaluated AEDs almost fully inhibited the occurrence of multiple spikes, without modifying the PS area. The number of additional spikes triggered by 4-AP could slightly vary from slice to slice, or according the electrodes within a single slice. Thus, the number of additional spikes triggered by $100 \mu \mathrm{M}$ 4-AP was 


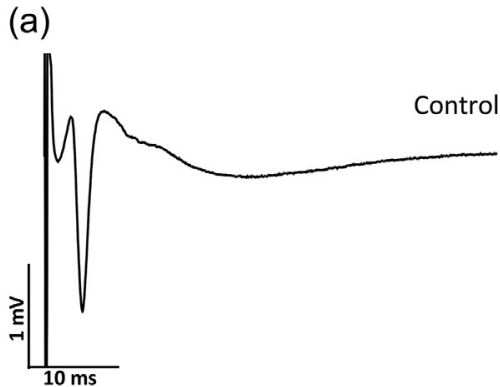

(b)

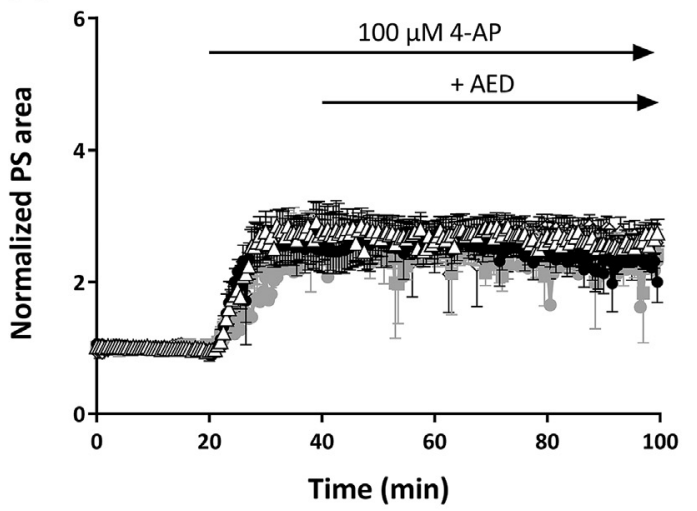

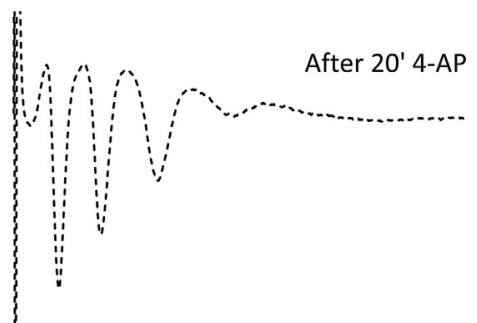

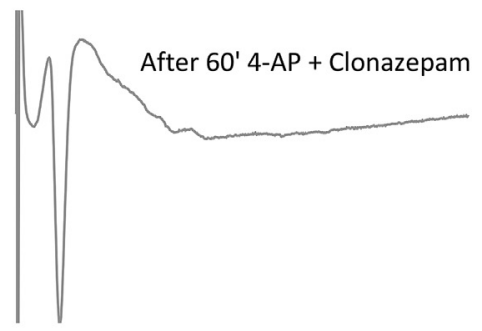

(c)

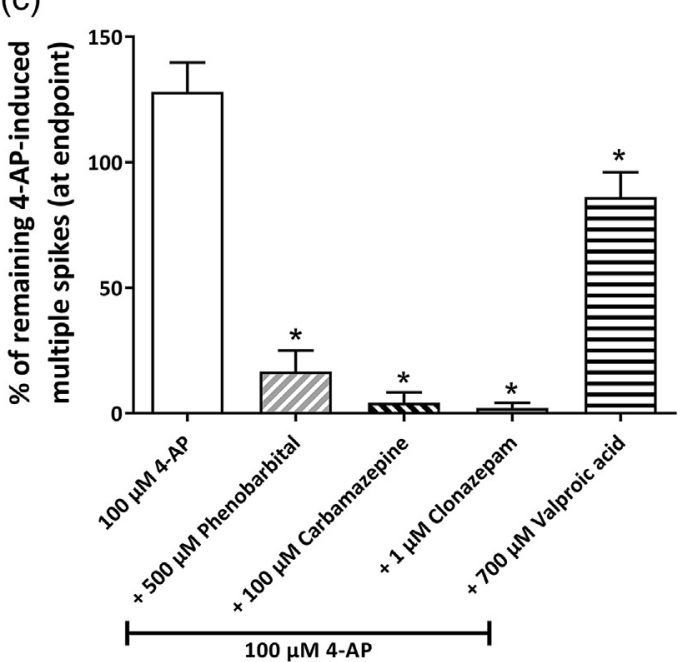

Fig. 2. Evaluation of phenobarbital, carbamazepine, clonazepam and valproic acid on 4-AP-induced change of PS shape and area.

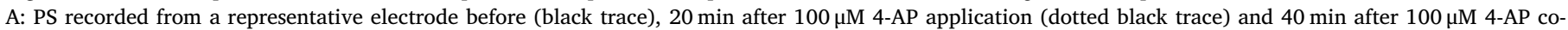
application with $1 \mu \mathrm{M}$ clonazepam (grey trace).

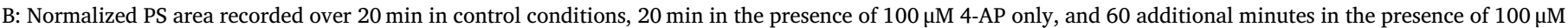

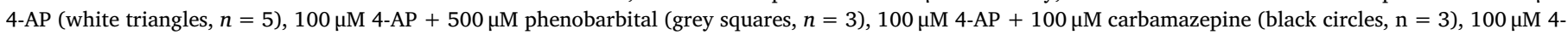
$\mathrm{AP}+1 \mu \mathrm{M}$ clonazepam (white diamonds line, $n=4$ ), $100 \mu \mathrm{M} 4-\mathrm{AP}+700 \mu \mathrm{M}$ valproic acid (grey circles, $\mathrm{n}=3$ ).

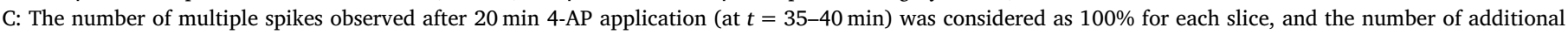

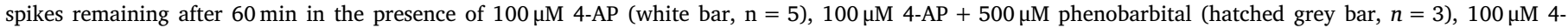

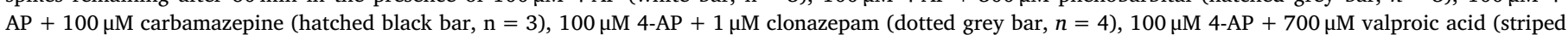

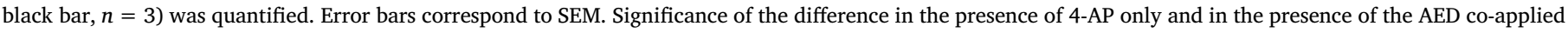
at $t=95-100 \mathrm{~min}$ is specified above bars (*, $\mathrm{p}<.01$; Mann-Whitney test).

considered as a $100 \%$, to be able to compare the effect of the different AEDs. $100 \mu \mathrm{M}$ phenobarbital, $100 \mu \mathrm{M}$ carbamazepine and $1 \mu \mathrm{M}$ clonazepam strongly decreased the number of additional spikes, by $83 \pm 8 \%, 96 \pm 4 \%$, and $98 \pm 2 \%$ respectively, in regards to the one at $t=35-40 \mathrm{~min}$ (Fig. 2C). This effect was significant for the $3 \mathrm{com}-$ pounds $(p=.0357, \mathrm{p}=.0357$ and $p=.0159$, respectively). $700 \mu \mathrm{M}$ valproic acid effect was more modest but was also significant $(\mathrm{p}=.0357)$. The number of spikes was decreased by $14 \pm 4 \%$ after a 60 -min co-application of $100 \mu \mathrm{M} 4-\mathrm{AP}$ and $700 \mu \mathrm{M}$ valproic acid, whereas in control slices exposed to 4-AP only, the percentage of additional spikes further increased, by $28 \pm 4 \%$, between $\mathrm{t}=35-40 \mathrm{~min}$ and $t=95-100 \mathrm{~min}$.

\subsection{In physiological conditions, 4-AP and carbachol triggered ED but not kainate and bicuculline}

The 4 reference proconvulsive compounds were applied on a naïve hippocampal slice, in absence of any kind of stimulation. The possible occurrence of epileptiform events was assessed with a MEA of whom electrodes cover the entirety of the hippocampal slice.

EDs correspond to a massive and synchronous discharge of a group of neurons over a large brain area, in the absence of any electrical stimulation. EDs rely on the ability of group of neurons to fire in synchrony. When a sufficient number of neurons that are connected fire or burst within the same time window, they mutually excite each other and trigger bursting in "follower" neurons. Group of neurons excites other groups of neurons in a cascade, until the majority of neurons from a large brain area fire in synchrony. Each neuron receives input from the other neurons before, during and after the bursting, thus causing the large depolarization that is recorded as ED bursting activity. Furthermore, EDs are associated with a local increase of the $\left[\mathrm{K}^{+}\right]_{\mathrm{ext}}$ (Avoli, Louvel, Kurcewicz, Pumain, \& Barbarosie, 1996; Colom \& Saggau, 1994). While this is a consequence rather than a cause of ED initiation, it is likely that the elevation of $\left[\mathrm{K}^{+}\right]_{\text {ext }}$ plays a role in the maintenance of recurrent epileptiform events.

$50 \mu \mathrm{M} 4-\mathrm{AP}(n=4)$ rapidly triggered EDs, after about $5 \mathrm{~min}$ of application. The frequency of 4-AP-induced EDs increased over about $10 \mathrm{~min}$, and then remained steady over a 60 -min period at around $0.3 \mathrm{~Hz}$ (Fig. 3A). 4-AP triggered EDs that occurred at regular intervals (Fig. 3C) and that could be observed over the whole hippocampal slices (in the DG, CA3 and CA1 hippocampal sub-fields, see Fig. 3B).

$10 \mu \mathrm{M}$ carbachol $(n=3)$ also triggered EDs after about 5 min of application. The rate of carbachol-induced EDs was lower than the one triggered by 4-AP (around $0.1 \mathrm{~Hz}$ ) but mainly they occurred with a different pattern (Fig. 3E). Carbachol-induced EDs consisted in a succession of episodes: 1 or 2 or EDs, occurring at long intervals (about $40 \mathrm{~s}$ 
(a)

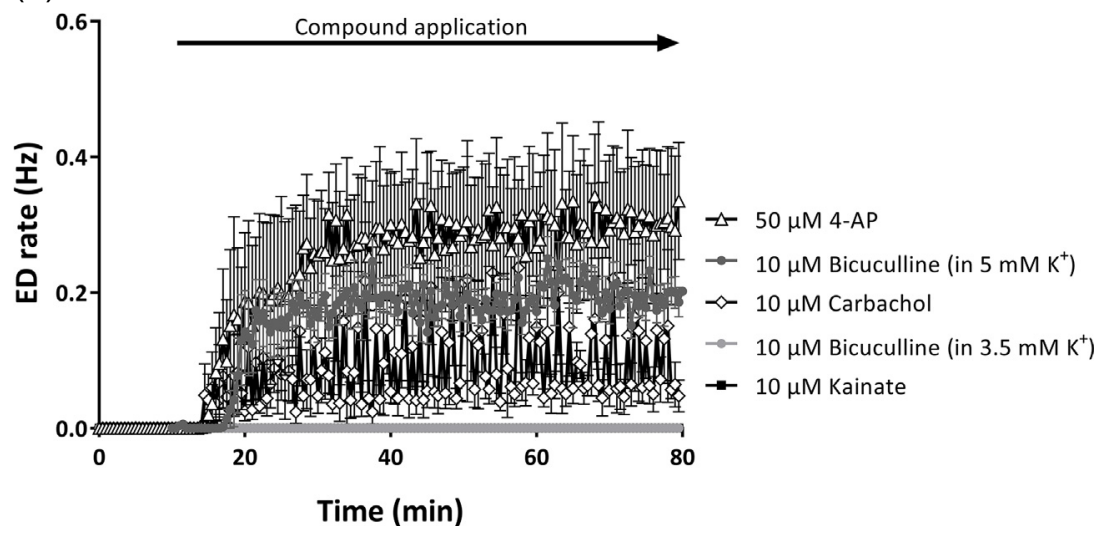

(c)

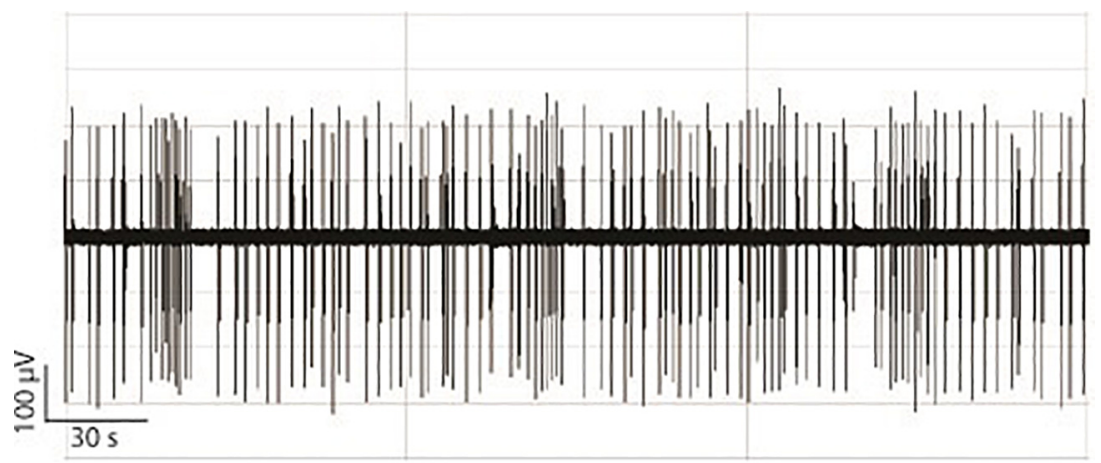

(d) (b)

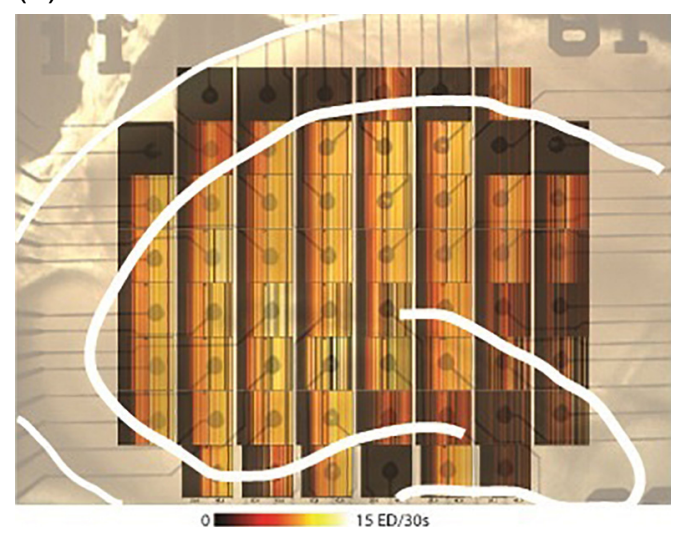

(d)

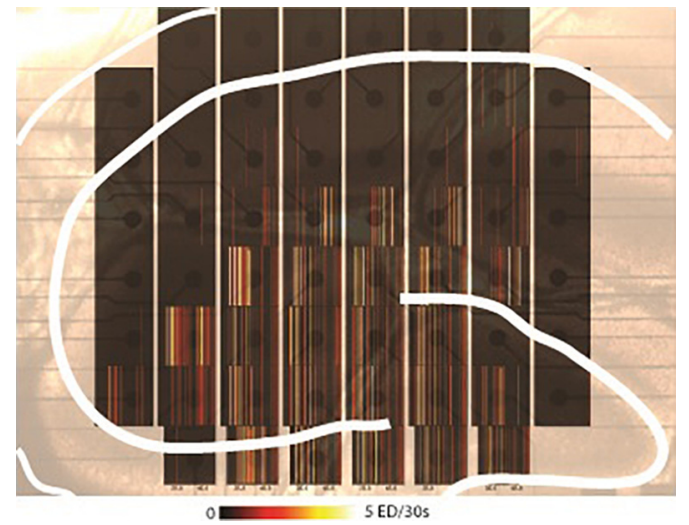

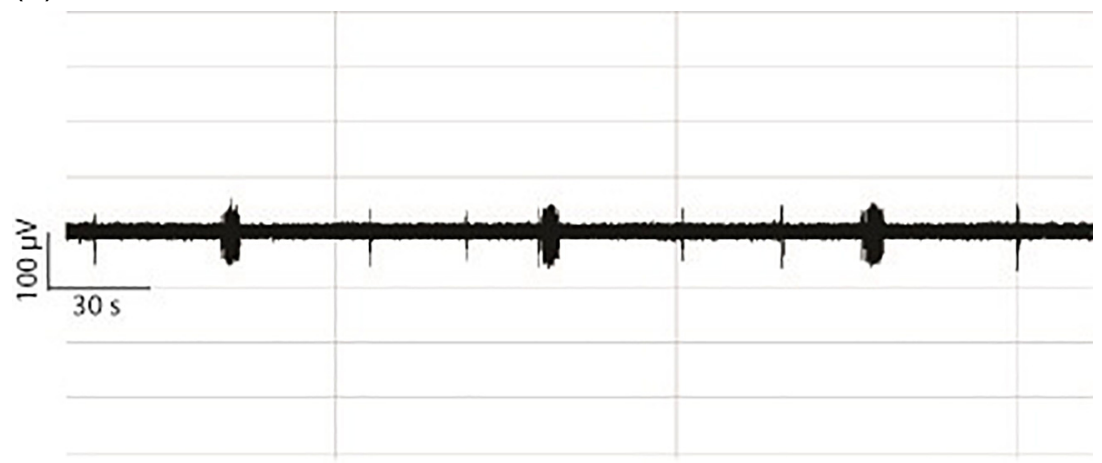

Fig. 3. Evaluation of propensity of bicuculline, 4-AP, kainate and carbachol to trigger EDs.

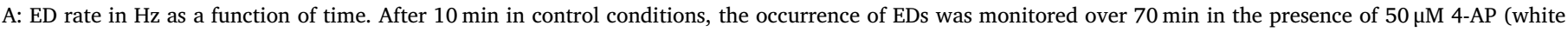

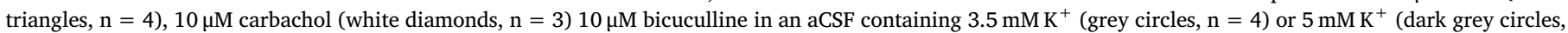
$n=5$ ) and $10 \mu \mathrm{M}$ kainate (black squares, $n=4$ ). Error bars correspond to SEM.

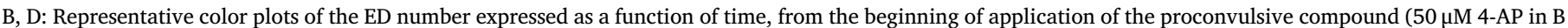

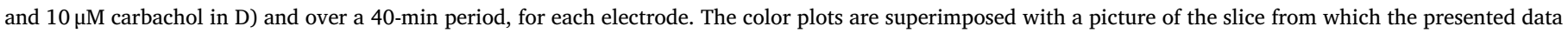

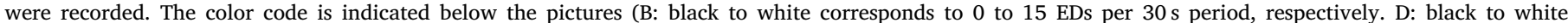
corresponds to 0 to 5 EDs per $30 \mathrm{~s}$ period, respectively).

C, E: Example of typical ED pattern occurring after application of $50 \mu \mathrm{M} 4$-AP (C) or $3 \mu \mathrm{M}$ carbachol (E). Vertical scale bar: $100 \mu \mathrm{V}$, horizontal scale bar: 30 s.

on average), followed a succession of numerous EDs in a restricted time window (about 20 EDs occurring within $4 \mathrm{~s}$ ). These EDs occurred mainly in the DG and CA3 subfield (Fig. 3D).

Under physiological conditions (in aCSF containing $3.5 \mathrm{mM} \mathrm{K}^{+}$), $10 \mu \mathrm{M}$ bicuculline $(n=4)$ and $10 \mu \mathrm{M}$ kainate $(n=4)$ did not trigger EDs. However, it is of value to note that bicuculline reliably elicited EDs occurring at a rate of $0.2 \mathrm{~Hz}$ when applied in an extracellular medium containing $5 \mathrm{mM} \mathrm{K}^{+}(n=5$, Fig. $3 \mathrm{~A})$, whereas no EDs were observed in control slices exposed to a medium containing $5 \mathrm{mM} \mathrm{K}^{+}$in the presence of vehicle only. As well, during the recordings of CA1 neuron firing, EDs occurred in all the hippocampal slices exposed to bicuculline when the extracellular $\mathrm{K}^{+}$concentration was raised to 7 or $10 \mathrm{mM}$, whereas no EDs were observed in control slices exposed to a medium containing 7 or $10 \mathrm{mM} \mathrm{K}^{+}$.

3.4. The 4 evaluated AED partially reversed 4-AP-induced ED with different potencies according to the hippocampal subfields

The effect of 4 AEDs (phenobarbital, carbamazepine, clonazepam and valproic acid) was assessed over a 40-min period on EDs triggered 
(a)

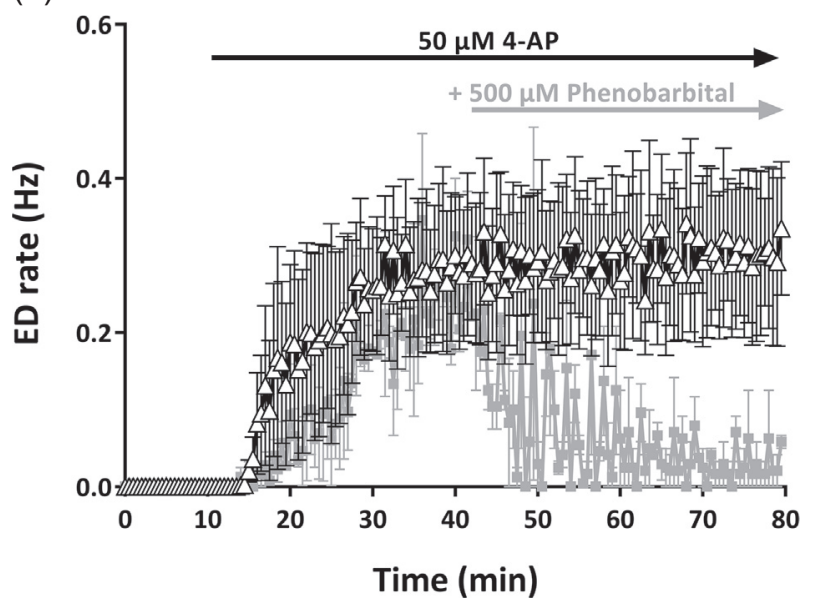

(b)

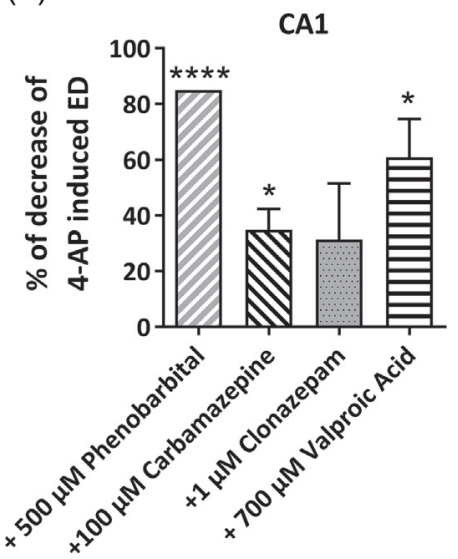

(c)

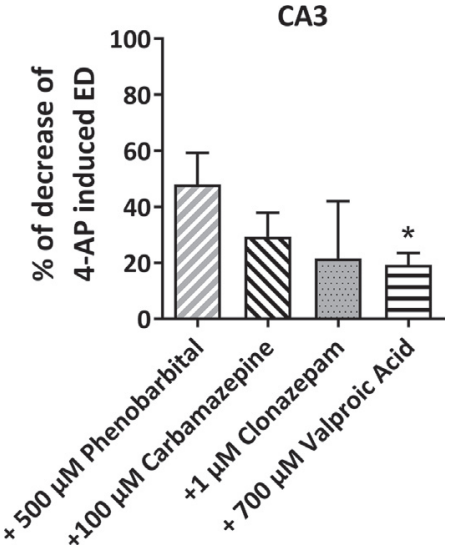

(d)

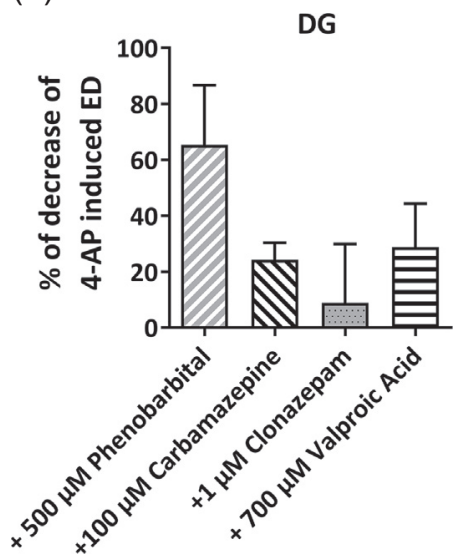

Fig. 4. Evaluation of phenobarbital, carbamazepine, clonazepam and valproic acid on 4-AP-induced EDs.

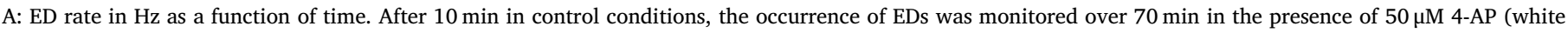
triangles, $\mathrm{n}=3$ ), or for $30 \mathrm{~min}$ in the presence of 4-AP only followed by $40 \mathrm{~min}$ of co-application with $500 \mu \mathrm{M}$ phenobarbital (light grey squares, $\mathrm{n}=2$ ).

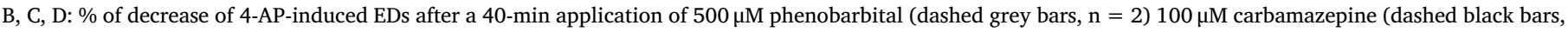

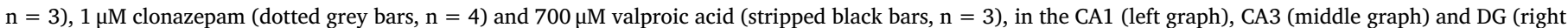

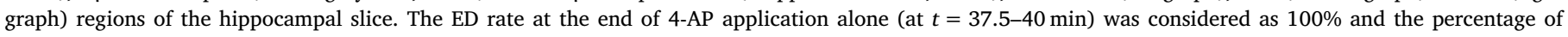

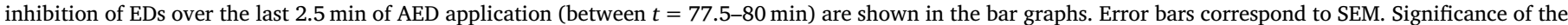
difference of ED rate before and 40 min after AED application is specified above bars (*, $\mathrm{p}<.05$; ****, $p<.0001$; paired Student's $t$-test).

by $50 \mu \mathrm{M}$ 4-AP.

Although these results should be confirmed from a larger number of samples, $500 \mu \mathrm{M}$ phenobarbital $(n=2$, Fig. 4A) efficiently $(p>.0001)$ inhibited EDs in the CA1 region (inhibition was almost complete after $20 \mathrm{~min}$ ). The percentage of EDs inhibition seemed however variable according to the hippocampal sub-fields (Fig. 4B, C, D): they were decreased by $85 \pm 0.002 \%, 48 \pm 11 \%$, and $65 \pm 21 \%$, in the CA1, CA3 and DG regions, respectively, in comparison with the control slices recorded in parallel.

$100 \mu \mathrm{M}$ carbamazepine $(n=3)$ partially inhibited the EDs and that effect was also larger and significant only in the CA1 region $(p=.0423)$. The rate of the EDs was decreased by $35 \pm 7 \%, 29 \pm 9 \%$ and $24 \pm 6 \%$ in the CA1, CA3 and DG regions, respectively.

After a 40-min application of $1 \mu \mathrm{M}$ clonazepam $(n=4)$, the ED rate was inhibited $31 \pm 20 \%, 22 \pm 20 \%$ and $9 \pm 21 \%$ in the CA1, CA3 and DG regions, respectively. Due to variability of the results, this slight effect on the ED rate was significant in none of the 3 hippocampal regions.

Over a 40 -min period, $700 \mu \mathrm{M}$ valproic acid $(\mathrm{n}=3)$ was more effective than $1 \mu \mathrm{M}$ clonazepam, especially in the CA1 region, where it significantly decreased the EDs $(p=.0476)$. It decreased the ED rate by $61 \pm 14 \%, 19 \pm 4 \%$ and $29 \pm 16 \%$ in the CA1, CA3 and DG regions, respectively.

\subsubsection{Carbachol, kainate and 4-AP but not bicuculline increased firing of CA1 neurons}

In the CA1 region of the hippocampus, the pyramidal neurons are arranged in a dense layer that forms the stratum pyramidale. These neurons fire spontaneously in physiological conditions. As shown in Fig. 5A, the firing rate is correlated to the extracellular $\mathrm{K}^{+}$level: it increases proportionally to the $\mathrm{K}^{+}$concentration in the perfused aCSF (3.5, 7 or $10 \mathrm{mM})$.

4 reference proconvulsive compounds were evaluated on the CA1 neuron firing rate in aCSF containing $3.5 \mathrm{mM}, 7 \mathrm{mM}$ and $10 \mathrm{mM} \mathrm{K}^{+}$. The aim of evaluating compounds in media with different $\mathrm{K}^{+}$concentrations, and then in different excitability conditions, was to determine if proconvulsive properties could be better revealed in neurons of which excitability is increased. The firing was first recorded in the presence of a $10 \mathrm{mM} \mathrm{K}^{+}$aCSF that triggers a sustained firing in all the evaluated slices. This initial period was used to normalize the data before any compound application. Next, the firing activity was recorded in physiological conditions for $40 \mathrm{~min}$ (in $3.5 \mathrm{mM} \mathrm{K}^{+} \mathrm{aCSF}$ ), in $7 \mathrm{mMK}^{+}$aCSF for $30 \mathrm{~min}$ and in $10 \mathrm{mMK}^{+}$aCSF for $30 \mathrm{~min}$. Compounds to be evaluated were applied on the slice for $30 \mathrm{~min}$ in each 
(a)
$3.5 \mathrm{mM}\left[\mathrm{K}^{+}\right]_{\mathrm{ext}}$
$7 \mathrm{mM}\left[\mathrm{K}^{+}\right]_{\mathrm{ext}}$
$10 \mathrm{mM}\left[\mathrm{K}^{+}\right]_{\mathrm{ext}}$

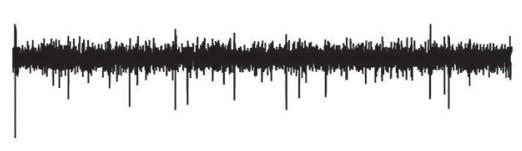

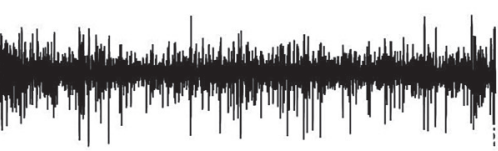

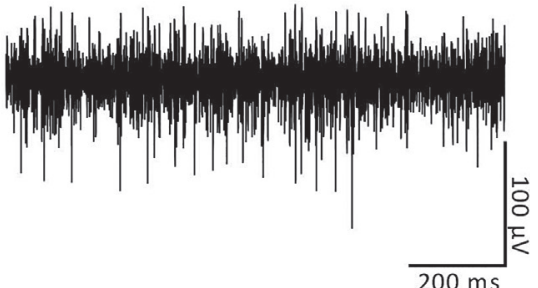

(b)

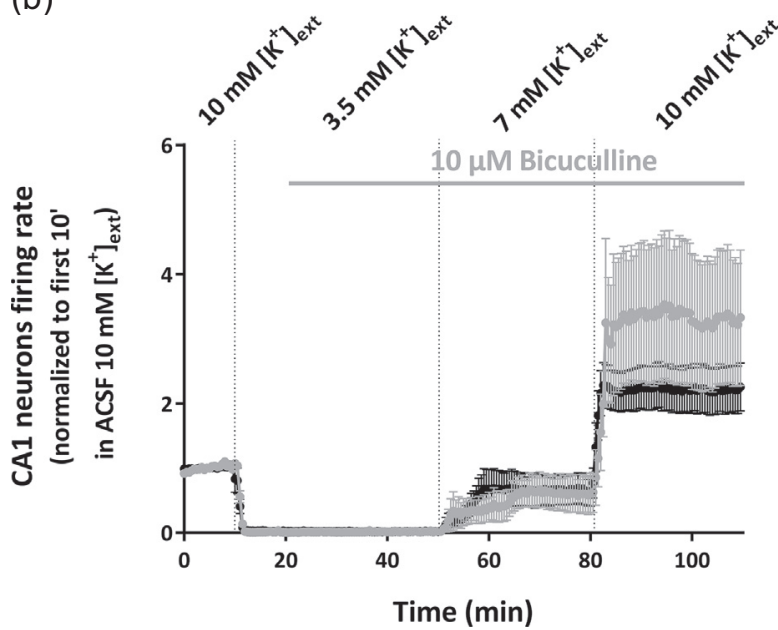

(d)

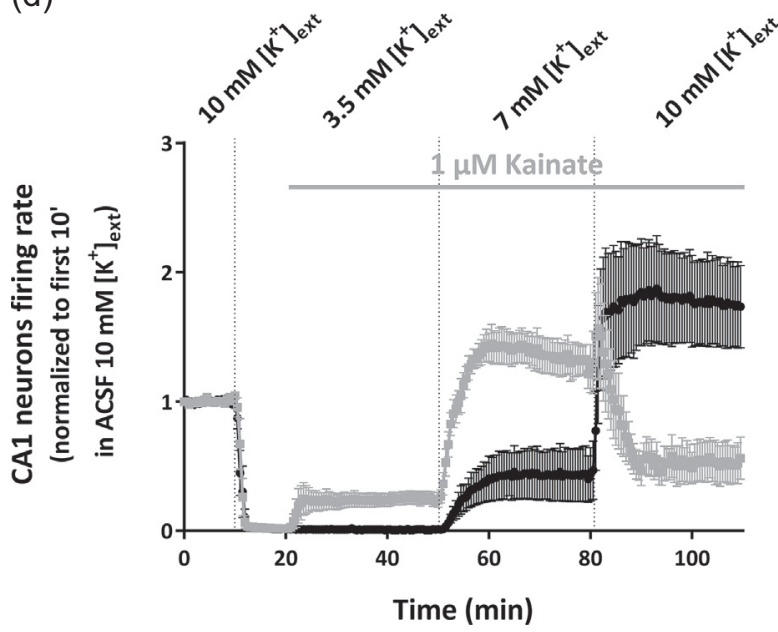

(c)

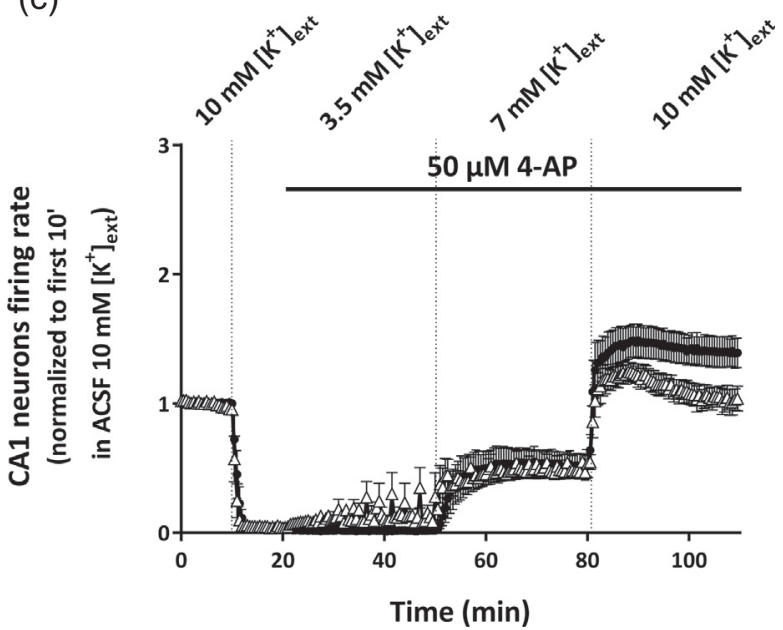

(e)

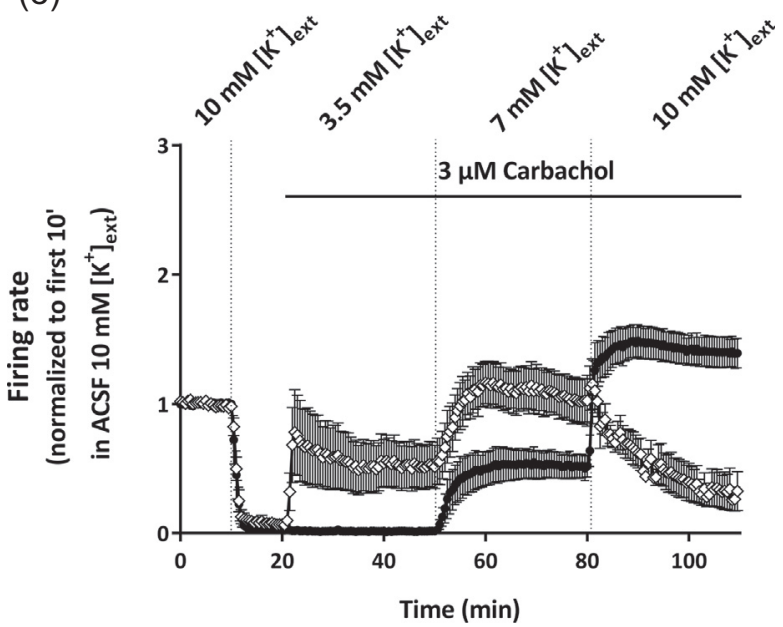

Fig. 5. Evaluation of bicuculline, 4-AP, kainate and carbachol effect on CA1 neuron firing in different excitability conditions.

A: Representative traces of CA1 neuron firing in aCSF containing 3.5, 7 or $10 \mathrm{mM} \mathrm{K}^{+}$.

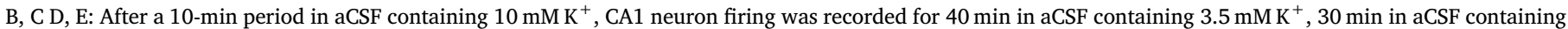

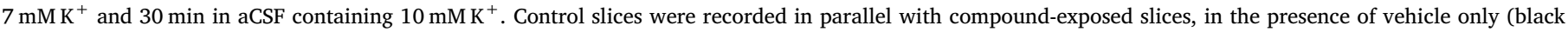

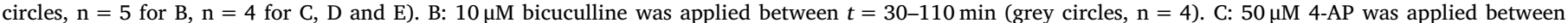

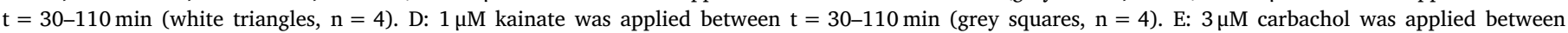

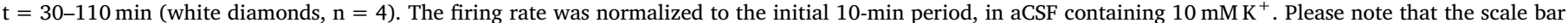
was larger for B graph than for C, D and E graph. Error bars correspond to SEM.

aCSF (from $t=20 \mathrm{~min}$ to $t=110 \mathrm{~min}$ ). Control slices prepared from the same rats were recorded in parallel, over equivalent time periods, in the presence of vehicle only. It is of value to note that the firing triggered by the second exposure to a $10 \mathrm{mM} \mathrm{K}^{+}$aCSF was not equivalent to the one observed during the initial exposure to $10 \mathrm{mM} \mathrm{K}^{+}$aCSF: it systematically displayed a higher rate.

$10 \mu \mathrm{M}$ bicuculline $(n=4)$ did not significantly modified the firing rate of CA1 neurons whatever was the extracellular $\mathrm{K}^{+}$concentration: after a $25 / 30-\mathrm{min}$ application of bicuculline in $3.5,7$ or $10 \mathrm{mM} \mathrm{K}^{+}$, the mean normalized firing was $0.017 \pm 0.010,0.596 \pm 0.286$ and $3.314 \pm 1.021$, versus $0.020 \pm 0.008, \quad 0.661 \pm 0.228$ and $2.218 \pm 0.411$ in control conditions $(n=4)$, over equivalent periods (Fig. 5B). However, EDs started to occur when the perfusion media $\mathrm{K}+$ concentration was raised to $7 \mathrm{mM}$, for all the hippocampal slices 
exposed to bicuculline, and the EDs prolonged up to the end of recording session (in 7 and $10 \mathrm{mM} \mathrm{K}^{+}$extracellular media).

$50 \mu \mathrm{M}$ 4-AP $(n=4)$ significantly $(p=.0286)$ increased the firing rate in physiological condition: after a $25 / 30$-min application of 4-AP, the mean normalized firing rate was $0.134 \pm 0.016$, versus $0.015 \pm 0.003$ in control conditions ( $n=5$, Fig. 5 C). It is of value to note that EDs started about $5 \mathrm{~min}$ after the beginning of 4-AP application for all the hippocampal slices exposed to this compound. However, the normalized firing rate remained in the same range as in matching control slices in $7 \mathrm{mMK}^{+}$and $10 \mathrm{mMK}^{+}(0.490 \pm 0.053$ and $1.033 \pm 0.088$, versus $0.517 \pm 0.094$ and $1.397 \pm 0.116$ in control slices) and did not significantly differ.

$1 \mu \mathrm{M}$ kainate $(n=4)$ clearly increased the firing rate of the pyramidal neurons both in $3.5 \mathrm{mM}$ and $7 \mathrm{mM} \mathrm{K}^{+}$extracellular media: The mean normalized firing was $0.25 \pm 0.047$ and $1.314 \pm 0.127$ over the last five minutes of each period, respectively, versus $0.008 \pm 0.004$ and $0.430 \pm 0.204$, in control conditions $(n=4)$, over the equivalent periods of time (Fig. 5D). Kainate effect was significant in $3.5 \mathrm{mM} \mathrm{K}^{+}$ ( $p=.0286)$, but just failed to reach significance in $7 \mathrm{mM} \mathrm{K}^{+}$ $(p=.0571)$. When the perfusion medium containing $10 \mathrm{mMK}^{+}$was applied, the firing rate further increased over 2-3 min and then largely decreased to stabilize around 0.5 at endpoint $(0.523 \pm 0.155$, versus $1.749 \pm 0.330$ in control conditions, significant difference $p=.0286$ ).

$3 \mu \mathrm{M}$ carbachol $(n=4)$ strongly increased the CA1 neuron firing rate in a $3.5 \mathrm{mM} \mathrm{K}^{+}$aCSF: it reached a value larger than the one observed in a $7 \mathrm{mM} \mathrm{K}^{+}$aCSF in control conditions (after a 25/30-min application of $3 \mu \mathrm{M}$ carbachol, the normalized firing rate was $0.520 \pm 0.172$, versus $0.015 \pm 0.003$ in control conditions, $n=4$, Fig. 5E). The firing rate further increased in a $7 \mathrm{mM} \mathrm{K}^{+}$aCSF, it was $1.035 \pm 0.169$, versus $0.517 \pm 0.094$ in control conditions over the last five minutes in this aCSF. As observed with kainate, when $3 \mu \mathrm{M}$ carbachol was applied in a $10 \mathrm{mM} \mathrm{K}^{+}$solution, the firing rate first transiently increased for a few seconds, and then largely decreased and stabilized around values lower than in control slices (over the last five minutes of the recording session, the normalized firing was $0.317 \pm 0.131$ in the presence of carbachol, versus $1.397 \pm 0.116$ in matching control slices). Due to the variability of carbachol effect, the firing rate significantly differ from the one in control slices in $10 \mathrm{mM} \mathrm{K}^{+}$aCSF only $(\mathrm{p}=.0286)$.

\subsubsection{Phenobarbital and carbamazepine decreased the CA1 neuron firing} but not clonazepam and valproic acid

As for previous parameters (PS area and shape and ED frequency) the effect of the 4 reference anticonvulsants were evaluated on the firing of CA1 neurons (Fig. 6).

$500 \mu \mathrm{M}$ phenobarbital $(n=4)$ clearly decreased the firing rate of the CA1 neurons, whatever was the extracellular $\mathrm{K}^{+}$although it was more obvious when the firing was enhanced in aCSF containing $10 \mathrm{mM} \mathrm{K}^{+}$concentration. Thus, the normalized firing rate was $0.014 \pm 0.008,0.270 \pm 0.065$, and $0.550 \pm 0.065$ over the last five minutes of each 30-min application of $500 \mu \mathrm{M}$ Phenobarbital in 3.5, 7 and $10 \mathrm{mM} \mathrm{K}^{+}$containing aCSF, respectively, versus $0.055 \pm 0.005$, $0.586 \pm 0.065$ and $1.509 \pm 0.259$ in matching control slices $(n=3)$.

$100 \mu \mathrm{M}$ carbamazepine $(n=4)$ decreased the CA1 neuron firing, especially in aCSF containing $10 \mathrm{mM} \mathrm{K}^{+}$concentration. The normalized firing rate was $0.005 \pm 0.004,0.163 \pm 0.045$, and $0.136 \pm 0.070$ over the last five minutes of each 30-min application of $100 \mu \mathrm{M}$ carbamazepine in $3.5,7$ and $10 \mathrm{mM} \mathrm{K}^{+}$containing aCSF, respectively, versus $0.012 \pm 0.007,0.409 \pm 0.164$ and $2.093 \pm 0.670$ in matching control slices $(\mathrm{n}=3)$.

On the opposite, both clonazepam and valproic acid did not significantly modified the CA1 neuron firing rate.

In the presence of $1 \mu \mathrm{M}$ clonazepam $(n=3)$, the normalized firing rate was $0.027 \pm 0.016,0.571 \pm 0.097$, and $1.480 \pm 0.163$ over the last five minutes of each 30-min application of this compound in 3.5, 7 and $10 \mathrm{mM} \mathrm{K}^{+}$containing aCSF, respectively, versus $0.019 \pm 0.019$,
$0.477 \pm 0.032$ and $1.558 \pm 0.134$ in matching control slices $(n=3)$.

In the presence of $700 \mu \mathrm{M}$ valproic acid $(n=5)$, the normalized firing rate was $0.027 \pm 0.010,0.564 \pm 0.130$, and $1.324 \pm 0.078$ over the last five minutes of each 30-min application of this compound in $3.5,7$ and $10 \mathrm{mM} \mathrm{K}^{+}$containing aCSF, respectively, versus $0.091 \pm 0.071,0.708 \pm 0.208$ and $1.464 \pm 0.138$ in matching control slices $(n=4)$.

\section{Discussion}

Drug-induced seizures are estimated to represents $6 \%$ of new-onset seizures and 9\% of status epilepticus (Chen, Albertson, \& Olson, 2016). As discussed earlier, a reliable assay to detect proconvulsive properties of compounds in the early stage of drug development and to make the drug development more effective is lacking. Such process improvement is needed so that pharmaceutical companies focus on the most promising and safer compounds, and advance new drugs with a higher benefit/risk ratio. Although some assays to detect proconvulsive properties exist, they have limitations. In vivo assays cause substantial animal suffering (especially MEST and PTZ tests). It is ethically desirable to replace these in vivo assays with predictive in vitro assays. Furthermore, in vitro assays enable mechanism of action studies owing to the large set of reference pharmacological compounds available.

What makes a compound proconvulsive or seizurogenic? This question could be addressed at the molecular, cellular, network levels. Beyond the classical unbalance of excitation/inhibition and increased neuronal excitability (Federico \& MacVicar, 1996; Johnston \& Brown, 1981), anything that enhances synchrony in groups of neurons will favor epileptic events (Menendez de la Prida, Huberfeld, Cohen, \& Miles, 2006; Schwartzkroin, 1994). This is why using a model system where the native neuronal network is intact is paramount. The hippocampal slice is an appropriate model system. The hippocampus is especially prone to trigger epileptic events both in vitro and in vivo (Lothman, 1994). In addition, main synaptic connections between hippocampal neurons are preserved while preparing transverse slices. Although some connections are severed during slices preparation, the connectivity between DG, CA3 and CA1 neurons are maintained in acute slices, as well as the recurrent inputs of CA3 neurons that are crucial for network synchronization and seizure initiation (Swann \& Gomez-Di Cesare, 1994). Having this connectivity preserved is of particular importance for investigating compounds triggering "repetitions" or synchronizations in the network (Schwartzkroin, 1994). Furthermore, in hippocampal slices all the principle neurons, interneurons, glia are in place and express native receptors, channels, enzymes, proteins from signaling pathways, etc. Glia plays an important role in the genesis and maintenance of EDs as it buffers ions in the extracellular space, in normal and pathological states (Lux, Heinemann, \& Dietzel, 1986). Finally, the hippocampus expresses an extremely wide panel of proteins. Although all the brain proteins could not be present within a single brain structure, using hippocampal slices maximize the probability that some compounds target(s) is(are) present. The hippocampal brain region is often a focus for epilepsy onset and/or spreading (Colom \& Saggau, 1994) but many types of epilepsies, such as absence epilepsy, are independent from the hippocampus. However, the aim of the assays presented here was to document proconvulsive properties of compounds based on a model network displaying a high propensity to trigger epileptic events.

Synchonization between neurons rely on electrical and chemical signaling. Electrophysiology is the technique of choice to investigate the effect of compounds on neuronal functions. The use of MEAs provides multipoint recordings allowing the detection of synchronized neuronal activities. In addition, the effect of compounds could be investigated over large brain areas and region selective effect could be documented. The MEA technique affords moderate throughput for testing compounds, exceeding the single electrode recording. Also MEA-based assays require low quantities of compound (in the range of 
(a)

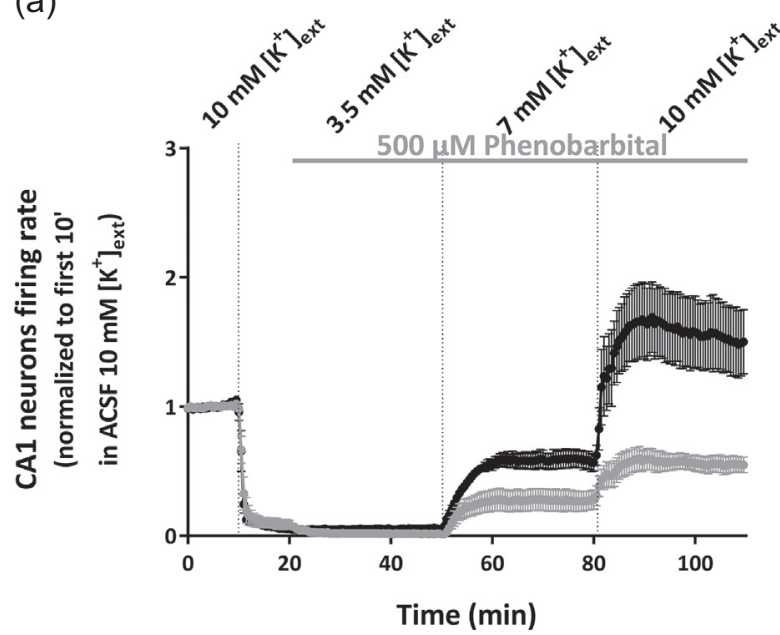

(c)

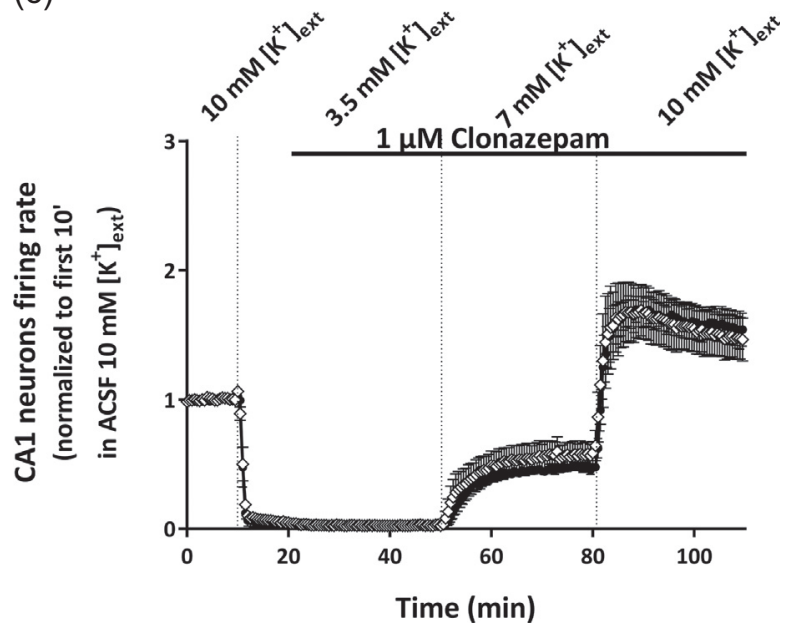

(b)

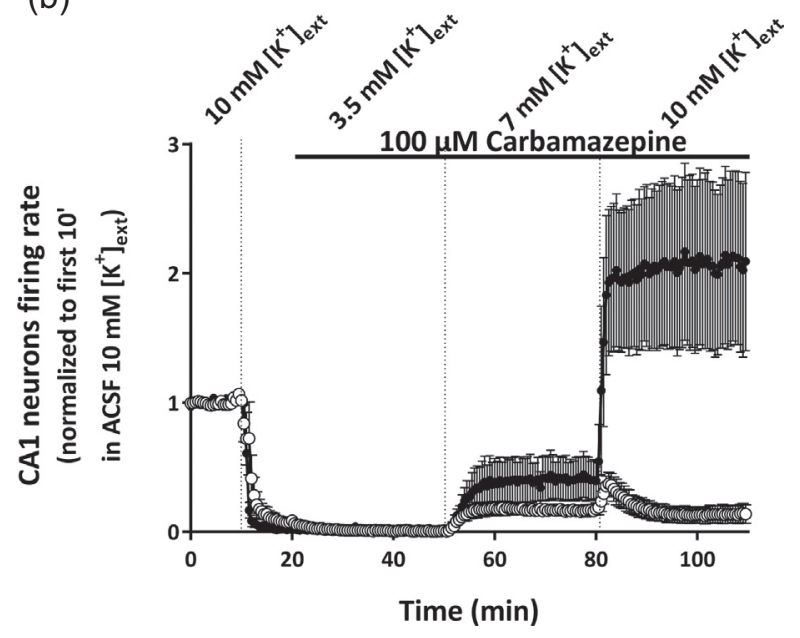

(d)

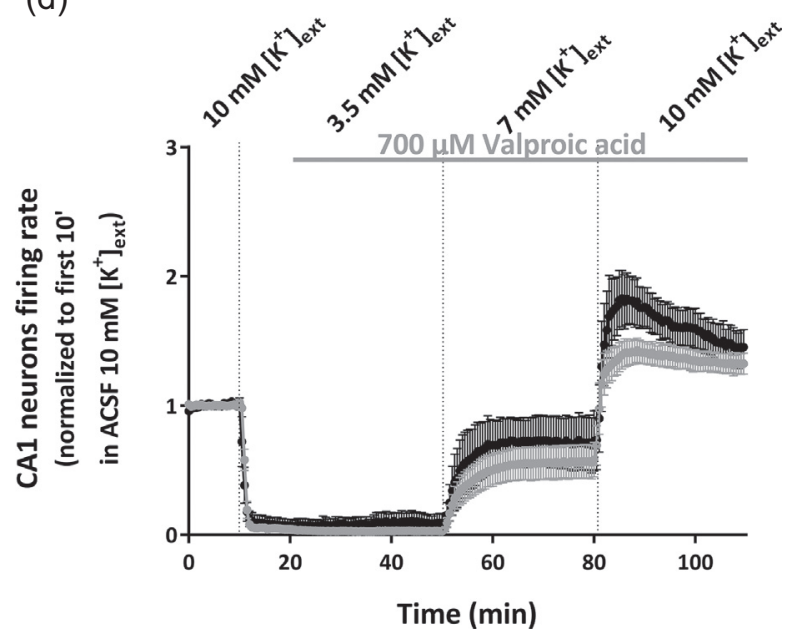

Fig. 6. Evaluation of phenobarbital, carbamazepine, clonazepam and valproic acid on CA1 neuron firing in different excitability conditions.

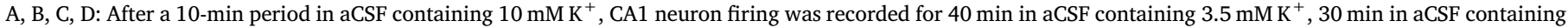

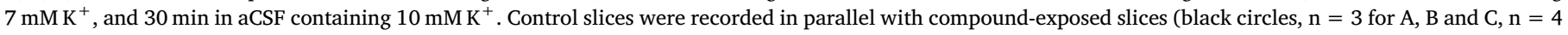

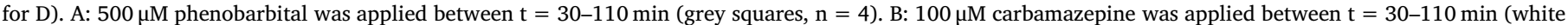

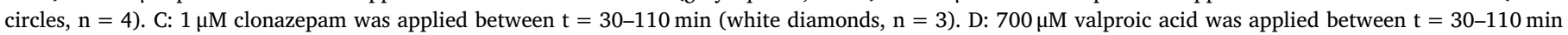
(grey circles, $\mathrm{n}=5$ ). The firing rate was normalized to the initial 10 -min period, in aCSF containing $10 \mathrm{mM} \mathrm{K}^{+}$. Error bars correspond to SEM.

few $\mathrm{mg}$ ) that are compatible with the quantities available in the early phases of development.

The first step of this work consisted in investigating and systematically comparing the effects of four reference proconvulsive or seizurogenic compounds on the main neuronal properties involved in seizure risk: neuronal excitability, balance of excitatory/inhibitory synaptic transmission, occurrence of neuronal synchronization mechanisms materialized by epileptiform discharges (EDs). The reference proconvulsive compounds that were evaluated displayed one or several of the following effects: they increased the CA1 neuron firing rate, they triggered multiple PS and increased the PS area and they triggered spontaneous ED that occurred synchronously over the hippocampal network.

\subsection{Most of evaluated proconvulsive compounds increase the PS area and trigger multiple spikes in response to a single stimulation}

Population spike (PS) area and shape were determined to be sensitive readouts of proconvulsive or seizurogenic compound activity. Indeed, most of the evaluated reference proconvulsive compounds triggered multiple spikes in response to a single stimulation and increased the PS area.

$100 \mu \mathrm{M} 4-\mathrm{AP}, 10 \mu \mathrm{M}$ bicuculline, and $300 \mathrm{nM}$ kainate increased the PS area: It was respectively increased by 4 -fold, 3 -fold and about $10 \%$, consistently with their mechanism of action.

While stimulating Schaffer collaterals, both GABAergic interneurons and CA1 pyramidal neurons are depolarized, the firsts temporally limiting the excitation/depolarization of the seconds. By blocking $\mathrm{GABA}_{\mathrm{A}}$ receptors, bicuculline relieved the inhibitory drive of interneurons on principle pyramidal neurons, which resulted in stronger and longer depolarizations of CA1 neurons following stimulation of afferent pathway. Thus, instead of generating a single spike, CA1 neurons displaying a longer depolarization in the presence of bicuculline generate several spikes.

4-AP enhances neurotransmitter release both at glutamatergic and GABAergic synapses (Buckle \& Haas, 1982). Because of the prominence of excitatory versus inhibitory input on CA1 pyramidal neurons, the net effect of 4-AP on CA1 pyramidal neurons is an increase of the postsynaptic depolarization, thereby causing a larger PS (Rowan, 1984). In addition, the intrinsic excitability of CA1 pyramidal neurons being increased due to the block of potassium channels by 4-AP (Rama et al., 2017), multiple spikes occur in response to a single stimulation. 
Kainate directly and selectively activates the ionotropic kainate receptors, causing a larger depolarization in the post-synaptic CA1 neurons when Schaffer collaterals are stimulated. This larger depolarization is accountable for the increase of PS area and the occurrence of one additional spike, on average. Kainate was finally evaluated at $300 \mathrm{nM}$ on the PS parameter, but it was initially tested at $1 \mu \mathrm{M}$. However, at such concentration, it largely decreased the PS area. PS inhibition in the presence of $1 \mu \mathrm{M}$ kainate did not entail irreversible excitotoxic mechanisms as a full recovery of PS was observed at washout. It is likely due to desensitization of receptors (Tasker et al., 2002), depolarization block (Lees \& Sandberg, 1991) and local ionic disturbances in the extracellular medium (mainly an increase of $\mathrm{K}^{+}$and a decrease of $\mathrm{Ca}^{2+}$, Lipski, Bellingham, West, \& Pilowsky, 1988) following a prolonged kainate receptors activation.

These results were expected from literature data. Consistent with our results, 4-AP enhanced the PS area (Accardi et al., 2018; Easter et al., 2007; Easter et al., 2009). Although the 3 other compounds (bicuculline, kainate and carbachol) were not evaluated in Easter and Accardi studies, proconvulsive or seizurogenic compounds tested (4-AP, picrotoxin, PTZ, penicillin, aminophylline, chlorpromazine, SNC-80, penicillin, cephazolin, enoxacin, isoniazid, strychnine) significantly increased the PS area. Our observations were then consistent with these studies. However, some proven proconvulsive compounds were not detected with this assay (bupropion, maprotiline, pilocarpine) or borderline (physostigmine).

In contrast to other evaluated compounds, $3 \mu \mathrm{M}$ carbachol decreased the PS area. Interestingly, carbachol displays opposite effects on CA1 pyramidal neurons according to the considered neuron region. When applied in the low micromolar range, despite it increases CA1 neuron firing activity (McQuiston, 2010) it decreases EPSP (and by consequence the PS) by activating pre-synaptic M1 receptors. Indeed, carbachol effect on EPSP was fully inhibited by the selective M1 antagonist atropine (Hasselmo and Schnell, 1994; Valentino and Dingledine, 1981). Thus, carbachol displays depolarizing effect at the somatic level, whereas at the dendritic level, it elicits a decrease of the evoked-responses, likely due a decrease of glutamate release at CA3 neurons synapses (McQuiston, 2010).

More importantly than the PS area, 4-AP, bicuculline and kainate triggered multiple PS in a response to a single stimulation: around 3, 4 and 1 additional spikes were observed after application of these compounds, respectively. At the evaluated concentration $(3 \mu \mathrm{M})$, carbachol did not trigger multiple PS, consistently with its depressing effect on evoked-responses at the dendritic level of pyramidal neurons.

The occurrence of multiple spikes in response to a single stimulation appeared as a more relevant hallmark for a proconvulsive compound than the compound effect on the PS area. Indeed, the occurrence of multiple spikes when a single spike would be expected could be one of the cellular mechanisms involved in neuronal synchronization in epilepsy. In addition, the effect of proconvulsive compounds on the number of spikes could be fully reversed in the presence of AEDs, whereas their effect on PS area remained unchanged by AEDs.

Phenytoin, carbamazepine, clonazepam and valproic acid were tested on PS displaying multiple spikes after $100 \mu \mathrm{M}$ 4-AP application. $100 \mu \mathrm{M}$ 4-AP was used for these experiments instead of $50 \mu \mathrm{M}$ for the recording of CA1 neuron firing or EDs as it was more convenient to quantify the AED effect. Indeed, $50 \mu \mathrm{M}$ 4-AP effect was more variable and triggered a lower number of additional spikes.

Most of the AEDs evaluated (phenytoin, carbamazepine and clonazepam) were able to inhibit the occurrence of additional spikes. However, they remained devoid of effect on the PS area that was almost tripled after 4-AP application (see Fig. 2). Actually, the progressive disappearance of additional spikes in the presence of the AEDs occurred simultaneously with a progressive increase of the first peak area. A hypothesis would be that tested AEDs do not significantly change the overall number of spikes generated by CA1 neurons in the presence of 4-AP but considerably limit the occurrence of spike trains in response to a single stimulation. In absence of 4-AP, when a neuron is depolarized, $\mathrm{K}^{+}$channels activation prevent from further depolarization and thus limits spike trains (Froemke, 2010). In the presence of 4-AP, spike trains are then more likely to occur. Both phenobarbital and clonazepam target $\mathrm{GABA}_{\mathrm{A}}$ receptors, by enhancing the duration of channel opening or its frequency, respectively. They were able to limit trains of spikes and counteracted some of 4-AP effects. Carbamazepine is a use-dependent sodium channel blocker. It binds preferentially to voltagegated sodium channels and inhibits high-frequency trains of AP much more potently than it attenuates firing at low frequencies or individual AP. It is particularly effective to inhibit AP superimposed on a depolarized plateau potential as it occurs in the case of seizures (Rogawski, Löscher, \& Rho, 2016). Complementary patch-clamp experiments would be of help to better understand how these AEDs modulate the frequency and timing of CA1 neurons firing in the presence of 4-AP.

Valproic acid only modestly reversed the multiple spikes triggered by 4-AP. As the other tested AEDs, valproic acid failed to reverse the increase of PS area triggered by 4-AP.

Interestingly, in the article from Easter et al. (Easter et al., 2007) the reference proconvulsive compound PTZ and SNC-80 also triggered one or several additional spikes at the same time they increased the PS area. Unlike these compounds, physostigmine did not significantly modified the PS area between 0.1 and $300 \mu \mathrm{M}$ and was then referenced as a false negative in this assay. However, the modification of PS shape triggered by physostigmine was commented by the author, and the figure illustrating the physostigmine effect on PS showed that the absence of significant effect on the PS AUC resulted from a decrease of the first PS area concomitant with the emergence of an additional spike.

This further highlights the importance of monitoring multiple spike occurrence, a feature that is more sensitive and relevant than the increase of the PS area to characterize proconvulsive compounds, from our point of view.

\subsection{Most of evaluated proconvulsive compounds trigger ED in hippocampal} slices

$10 \mu \mathrm{M}$ bicuculline did not trigger EDs on naïve hippocampal slices of young rats in physiological conditions (with an extracellular $\mathrm{K}^{+}$concentration equal to $3.5 \mathrm{mM}$ ). However, in experimental conditions where the excitability was increased (by raising the extracellular $\mathrm{K}^{+}$ concentration to $7 \mathrm{mM}$ ), EDs occurred in all the slices that were exposed to $10 \mu \mathrm{M}$ bicuculline (four out of four slices, observation made during the recording of CA1 neuron firing) whereas none of the five control slices recorded in parallel in the presence of vehicle only displayed EDs in $7 \mathrm{mM} \mathrm{K}^{+}$aCSF. The frequency of EDs in the presence of $10 \mu \mathrm{M} \mathrm{bi-}$ cuculline was further increased in $10 \mathrm{mM} \mathrm{K}^{+}$aCSF.

Additional experiments performed in aCSF containing $5 \mathrm{mM} \mathrm{K}^{+}$ confirmed that $10 \mu \mathrm{M}$ bicuculline triggered EDs occurring at a stable rate over a 1-h period (see Fig. 3). These results are consistent with literature data (Tancredi \& Avoli, 1987) documenting that $\mathrm{GABA}_{\mathrm{A}}$ antagonists' bicuculline and picrotoxin are unable to elicit EDs in physiological conditions, when the extracellular $\mathrm{K}^{+}$concentration is equal to $3.5 \mathrm{mM}$. However, the rate of EDs triggered by bicuculline is almost linearly related to the $\left[\mathrm{K}^{+}\right]_{\text {ext }}$ between $4.25 \mathrm{mM}$ (emergence of EDs, occurring at a low rate, around $0.02 \mathrm{~Hz}$ ) and $10.25 \mathrm{mM}$ (ED occurring at a high rate, around $0.65 \mathrm{~Hz}$ ).

As expected from literature data, $50 \mu \mathrm{M}$ 4-AP triggered robust EDs after a few minutes only. The EDs spread from the CA3 region to the whole hippocampal slice (Perreault \& Avoli, 1991, and Gonzalez-Sulser et al., 2011) and stabilized rapidly around $0.4 \mathrm{~Hz}$. EDs occurred with a very regular pattern all over the hippocampal sub-fields. 4-AP blocks $\mathrm{I}_{\mathrm{A}}$ and $I_{D}$ currents and increases excitability both in principle pyramidal neurons and in GABAergic interneurons, but the later are pivotal for the induction of EDs (Avoli \& de Curtis, 2011). The high propensity of CA3 pyramidal neurons to generate EDs in the presence of 4-AP is due to the recurrent excitatory connections among neighboring pyramidal cells, 
combined with the ability of CA3 neurons to generate voltage-gated $\mathrm{Ca}^{2+}$ bursting (Avoli et al., 2002; Schwartzkroin, 1994; Traub \& Jefferys, 1994; Traub \& Wong, 1981).

Kainate was initially tested at $1 \mu \mathrm{M}$ but did not elicited EDs at such concentration. Its concentration was then raised to $10 \mu \mathrm{M}$, but this compound failed to reproducibly elicit EDs in our experimental conditions. EDs occurred in a single slice out of the 3 slices exposed to $1 \mu \mathrm{M}$ kainate when the extracellular medium was switched to a $10 \mathrm{mM} \mathrm{K}^{+}$ aCSF (during experiment of CA1 neuron firing recording). However, kainate was reported to elicit EDs in in vitro brain slices in several published article (Yehezkel Ben-Ari \& Cossart, 2000; Fisher \& Alger, 1984; Lévesque \& Avoli, 2013). In addition, kainate receptors are highly expressed in the CA3 region of the hippocampus. In the nanomolar range, kainate both activates post-synaptic kainate receptors (containing GluR6) at mossy fiber synapses and increases tonic inhibition via the activation of GluR6-containing kainate receptors at glutamatergic synapses on GABAergic interneurons (Ben-Ari \& Cossart, 2000). The reasons of the apparent discrepancy with published data likely lies in the extracellular medium used for recordings. Indeed, in the study from Fisher (Fisher \& Alger, 1984), the aCSF used to bathe the slices contained $5 \mathrm{mM} \mathrm{K}^{+}$. Also, kainate might more easily trigger EDs in brain slices also containing other nucleus of the limbic system or preserving the connection with the entorhinal cortex (Avoli et al., 2002). Finally, the concentrations of kainate tested might be too high, as the literature describes EDs elicited in vitro by kainate concentrations around $300 \mathrm{nM}$.

$3 \mu \mathrm{M}$ carbachol was tested first but did not trigger spontaneous EDs. Then, the carbachol concentration was raised to $10 \mu \mathrm{M}$ and triggered EDs with a specific pattern: 2-3 low rate ED occurring at about $0.025 \mathrm{~Hz}$, followed a succession of EDs occurring at about $5 \mathrm{~Hz}$ over $4 \mathrm{~s}$ (thus with a frequency in the theta band; $4-12 \mathrm{~Hz}$ ). This pattern closely resemble the theta rhythms triggered by carbachol in vitro in hippocampal slices (Cataldi et al., 2011; Lévesque, Cataldi, Chen, Hamidi, \& Avoli, 2017; Williams \& Kauer, 1997). Although carbachol-induced theta rhythms in vitro was sometimes considered as a model of theta oscillations recorded in vivo, the cellular mechanisms responsible for the oscillatory activity substantially differ. Events triggered by carbachol rather correspond to interictal discharges observed in various models of epilepsy (Cataldi et al., 2011; Williams \& Kauer, 1997). Carbachol-induced EDs mainly results from M1 muscarinic receptors activation. $\mathrm{M} 1$ receptors enhance $\mathrm{Ca}^{2+}$-activated nonselective cation conductances. Together with high-voltage-activated $\mathrm{Ca}^{2+}$ channels, $\mathrm{Ca}^{2+}$-activated nonselective cation conductances may significantly contribute to the EDs observed during carbachol application (Fraser \& MacVicar, 1996). Williams et al. also showed that M1 and M3 muscarinic receptors activation promote membrane potential oscillations whereas M4 muscarinic receptors and nicotinic receptors may excite interneurons to shape oscillations into a theta rhythm (Williams \& Kauer, 1997).

All the evaluated AEDs partially reverse 4-AP-induced EDs, with different potencies according to the hippocampal subfields. $500 \mu \mathrm{M}$ phenobarbital was the most effective AED and almost fully inhibited EDs in the CA1 region within $40 \mathrm{~min}$. Inhibition of EDs remained partial after a 40 -min application of $700 \mu \mathrm{M}$ valproic acid, $100 \mu \mathrm{M}$ carbamazepine and $1 \mu \mathrm{M}$ clonazepam (by rank of efficacy). A longer time period might be required to achieve a more potent inhibition of the EDs with these compounds. Also, it is to note that ED inhibition seemed more effective in the CA1 region than in the CA3 or DG region for all the compounds tested.

The evaluation of reference AEDs confirmed the importance of monitoring the occurrence of EDs to evaluate the proconvulsive potential of compounds. In addition, EDs are of particular relevance to the proconvulsive potential of compounds since they correspond to a phenomenon occurring in vivo in epileptic animal and humans: the interictal spikes or interictal EDs. It is postulated that interictal EDs could participate to the genesis of the epileptic focus. Indeed, synchronous membrane depolarization and synaptic activity occurring during interictal EDs reinforce the strength of synaptic connection between neurons and might increase seizure probability (Staley, White, \& Dudek, 2011). In addition, almost all the compounds that elicit EDs in vitro in brain slice also trigger convulsions in animals or humans. For instance 4-AP caused seizures in humans after poisoning (Spyker, Lynch, Shabanowitz, \& Sinn, 1980) or during therapeutical trials of this drug (Thesleff, 1980) as in brain slices (Avoli et al., 1996; Rutecki, Lebeda, \& Johnston, 1987). So did bicuculline (de Feo, Mecarelli, \& Ricci, 1985), kainate (Fisher \& Alger, 1984) and carbachol (Cohen, Morley, \& Snead, 1981; Cruickshank, Brudzynski, \& McLachlan, 1994). The list of other compounds that both triggered seizures or convulsions in vivo and EDs in vitro in brain slices remains long (PTZ, pilocarpine, penicillin, SNC-80, aminophylline, picrotoxin, NMDA, soman - non exhaustive list). It seems that only DPCPX, an agonist of A1 adenosine receptors displaying strong proconvulsive properties, was reported to trigger ED in vitro but not seizures in vivo (Chesi \& Stone, 1997).

\subsection{Most of evaluated proconvulsive compounds increase CA1 neuron firing}

Among the 4 evaluated compounds, 4-AP, kainate and carbachol increased the firing of CA1 neurons, whereas bicuculline did not. However, the increase in neuronal firing differed according to the compounds, consistently with their mechanism of action.

The voltage-gated $\mathrm{K}^{+}$channel blocker 4-AP increased the firing in physiological condition (in an aCSF containing $3.5 \mathrm{mM} \mathrm{K}^{+}$aCSF). This $\mathrm{K}^{+}$concentration was determined as physiological as stated in an article of Lux et al. (Lux et al., 1986). 4-AP increases the $\mathrm{K}^{+}$gradient across the membrane, making it more depolarized, and extends the duration of the repolarization phase after an action potential (Mitterdorfer \& Bean, 2002). In aCSF containing $3.5 \mathrm{mM} \mathrm{K}^{+}$, the firing activity triggered by 4-AP was mostly synchronized for all the CA1 neurons and even over the whole hippocampal slice. The firing triggered by 4-AP mainly consisted in bursts occurring at regular intervals, following with the massive depolarization of group of neurons occurring during EDs. The firing activity however remained in the same range as in control slices when the extracellular $\mathrm{K}^{+}$concentration was raised to 7 or $10 \mathrm{mM}$. Indeed, in such extracellular solutions, $\mathrm{K}^{+}$gradients are decreased, and then mask the effect of 4-AP.

Kainate is a selective agonist for the kainate subtype of glutamate receptors that are expressed in CA1 and CA3 neurons (Vargas, Takahashi, Thomson, \& Wilcox, 2013). It directly activates glutamatergic neurons by causing a cationic influx through the cell membrane and depolarizing it up to the threshold triggering an action potential. In the presence of kainate, the firing rate remained higher than in control conditions in 3.5 and $7 \mathrm{mM}\left[\mathrm{K}^{+}\right]_{\mathrm{ext}}$, but the firing enhancement by kainate became smaller as the extracellular $\mathrm{K}^{+}$increased. Indeed, $7 \mathrm{mM}$ $\left[\mathrm{K}^{+}\right]_{\text {ext }}$ causes a depolarization of CA1 neurons membrane and an increase of the firing rate. In proportion, Kainate effect on firing was then weaker. In the presence of $10 \mathrm{mM}\left[\mathrm{K}^{+}\right]_{\mathrm{ext}}$, after an initial increase of the firing activity over about $2 \mathrm{~min}$, the firing rate drastically decreased. As discussed earlier, this decrease is not accountable to excitotoxicity but likely results from a combination of several mechanisms. Indeed, after a prolonged kainate application, a desensitization of the receptors could be observed (Tasker et al., 2002). In addition, sustained kainate receptor activation generate local ionic disturbances in the extracellular medium (mainly an increase of $\mathrm{K}^{+}$and a decrease of $\mathrm{Ca}^{2+}$ ) due to the depolarizing action of kainate (Lipski et al., 1988). Finally, "depolarization block" preventing CA1 neuron firing, is likely to occur in such experimental conditions. Indeed, kainate causing a massive influx of $\mathrm{Na}^{+}$ions combined with a high $\mathrm{K}^{+}$extracellular concentration favors a configuration in which the membrane potential remains "blocked" in a depolarized state: the membrane potential reaches an equilibrium value between $-40 \mathrm{mV}$ and $-35 \mathrm{mV}$, above the spike threshold, and inhibits subsequent firing (Bianchi et al., 2012; Lees \& Sandberg, 1991). 
Experiments with cyclothiazide, a pharmacologic reference compound preventing kainate receptors desensitization could be used to determine what part of this phenomenon is responsible for the firing decrease.

The profile of firing activity for the wide spectrum cholinergic receptors agonist carbachol was equivalent to the one observed in the presence of kainate. From literature, carbachol effect on CA1 neuron firing is mediated by muscarinic but not nicotinic receptors (nicotine has no direct effect on CA1 pyramidal neuronal excitability, (Cole \& Nicoll, 1983). Muscarinic receptors activation lead to blockade of Mcurrents and calcium-activated potassium conductances thereby reducing the accommodation of firing (Cole \& Nicoll, 1983). In addition, muscarinic agonists reduce the amplitude of afterhyperpolarization (Cole \& Nicoll, 1984) and facilitate the production of an afterdepolarization (Fraser \& MacVicar, 1996). All these actions result in a net increase of spontaneous firing. As observed for kainate, carbachol effect on firing (compared to control slices) was lower as the extracellular $\mathrm{K}^{+}$increased, likely due to the increase of resting membrane potential value between 3.5 and $7 \mathrm{mM}\left[\mathrm{K}^{+}\right]_{\text {ext }}$. In $10 \mathrm{mM}\left[\mathrm{K}^{+}\right]_{\text {ext }}$, after a transient increase lasting about $2 \mathrm{~min}$, the firing rate largely decreased. As discussed above, a desensitization of muscarinic receptors and establishment of a "depolarization block" could explain this effect.

Bicuculline did not modify the firing activity in the presence of 3.5 and $7 \mathrm{mM} \mathrm{K}^{+}$. Indeed, even if GABAergic interneurons modulate excitatory input on CA1 neurons, they apparently do not substantially modulate their spontaneous firing. In the presence of $10 \mathrm{mM} \mathrm{K}^{+}$, bicuculline slightly increased CA1 neuron firing. This slight difference with control slices is likely attributable to bursting activity associated with EDs that occurred in the presence of bicuculline.

It is of value to note that the firing triggered by the second exposure to a $10 \mathrm{mM} \mathrm{K}^{+}$aCSF systematically displayed a higher rate than the one observed during the initial exposure to $10 \mathrm{mM} \mathrm{K}^{+}$aCSF. The firing rate was about $50 \%$ larger over the second exposure to a $10 \mathrm{mM} \mathrm{K}^{+}$aCSF compared to the first one for control slices recorded in parallel with reference proconvulsive compounds (see Fig. 5). However, for control slices which were not exposed to $7 \mathrm{mM} \mathrm{K}^{+}$aCSF prior $10 \mathrm{mM} \mathrm{K}^{+} \mathrm{aCSF}$, the firing rate was only $10 \%$ larger over the second exposure to a $10 \mathrm{mM} \mathrm{K}^{+}$aCSF, when compared to the first one (data not shown). Several mechanisms might explain this phenomenon. Indeed, several applications of a high potassium medium ( 3 times $30 \mathrm{~s}$ application of $20 \mathrm{mM} \mathrm{K}^{+}$) was documented to induce a long lasting ( $>1 \mathrm{~h}$ ) increase of the CA1 neurons spikes in response to an electrical stimulation. This effect is mediated by an increase of the EPSP-spike transfer. Repeated exposure to high $\mathrm{K}^{+}$triggers neurotransmitter release and the potentiation of EPSP-spike transfer is dependent on NMDA receptors and on L-type voltage dependent calcium channels (Semyanov \& Godukhin, 2001; Semyanov, Morenkov, Savin, \& Godukhin, 1999). In addition, the expression of some channels at the neurons' membrane might be increased following the initial $10 \mathrm{mM} \mathrm{K}^{+}$application. Also spatial buffering of $\mathrm{K}^{+}$by glial cells and $\mathrm{Na}^{+} / \mathrm{K}^{+}$ATPase might be saturated in the presence of high $\mathrm{K}^{+}$(Durand, Park, \& Jensen, 2010). This last hypothesis might explain why the firing over the second $10 \mathrm{mM} \mathrm{K}^{+}$application is larger when it is preceded by a prolonged exposure to a $7 \mathrm{mM} \mathrm{K}^{+}$aCSF than when it is not. However, additional investigations should be conducted to draw conclusion about the mechanisms involved.

Among the 4 tested AEDs, both phenobarbital and carbamazepine strongly decreased the CA1 neuron firing, whereas valproic acid only modestly decreased it and clonazepam left it unaffected, irrespective of the extracellular $\mathrm{K}^{+}$concentration. This was consistent with their mechanism of action: Phenobarbital inhibits sodium currents and enhances GABAergic inhibition. However, positive or negative modulation of GABAergic input did not modify the CA1 neuron firing in our experimental conditions. Thus, phenobarbital effect on firing likely results from its inhibition of sodium currents. Carbamazepine is a usedependent inhibitor of sodium currents (it strongly inhibits sustained firing whereas scarce firing is much less inhibited). Consistently with this feature, carbamazepine inhibited firing by $58 \%$ and $60 \%$ in 3.5 and $7 \mathrm{mM}\left[\mathrm{K}^{+}\right]_{\text {ext }}$, whereas it was inhibited by $94 \%$ in $10 \mathrm{mM}\left[\mathrm{K}^{+}\right]_{\text {ext }}$. Valproic acid enhances GABAergic inhibition and also affects voltagegated sodium channels. The main mechanism responsible for its antiepileptic properties is thought to be via an increased GABAergic inhibition, hence the lack of significant difference with control slices. Clonazepam is a positive allosteric modulator acting at the benzodiazepine site of the $\mathrm{GABA}_{\mathrm{A}}$ receptors. Consistently with the lack of effect of $\mathrm{GABA}_{\mathrm{A}}$ receptors modulators on the CA1 firing, clonazepam did not modify the firing rate in comparison with the one in control slices, whatever was the extracellular $\mathrm{K}^{+}$concentration.

Evaluation of reference proconvulsive and AEDs confirmed the interest of investigating the effect of compounds on CA1 neuron firing: although not sufficient to draw conclusions about compound properties toward the network, the evaluation of their effect on neuron firing indicates if they modulate, positively or negatively, neuronal intrinsic excitability.

An enhanced neuronal firing would statistically increase the probability of synchronized presynaptic and postsynaptic firing that would result in a reinforcement of synaptic coupling between neurons and in an increased neurotransmission. If a sufficient number of neurons within the network have their activity and coupling increased this way, this could eventually lead to epileptic activity (Ben-Ari \& Gho, 1988; Debanne, Thompson, \& Gahwiler, 2006; Bains, Longacher, \& Staley, 1999).

\subsection{Limitations of our results}

It would be desirable to increase the sensitivity of this in vitro electrophysiological assay to detect even weak proconvulsive compounds. The aim of the present study was to identify the parameters of interest from compounds displaying strong proconvulsive properties. The assays need to be adjusted to be able to detect even compounds that are weak proconvulsive (by co-applying a low concentration of a reference pro-convulsive compound together with the compound to be tested, for instance).

The platform could be validated only once a least a 20-30 compounds will have been tested (including positive and negative controls). The evaluation of compounds that went through development phases (and thus with a quite good safety profile before the proconvulsive effects revealed) would be a clear added value to evaluate the predictability of this platform.

It might be difficult to select the right concentration of drug candidate to be tested in our assay at the beginning of development phases (when ADME or pharmacokinetic data not yet available). Systematically selecting a very high concentration could reveal proconvulsive properties that would not occur within the therapeutic window. Thus, it would be desirable to determine the effect of a doserange of each compound tested. This way, the threshold concentration triggering proconvulsive effects could be determined.

Although proconvulsive compounds tested on rat brain slices were detected most of the time, inter-species differences exists. Then, caution is needed before drawing any definitive conclusion from rat brain slice assays. Also, when using young rodent tissue, the target of the proconvulsive compound could be not yet expressed, or not at the level it would be in adults.

Finally, the hippocampal slice does not recapitulate the whole brain complexity, its connectivity is preserved in 2 dimensions only and the communication between septal and temporal part of the hippocampus is severed. The effect of a compound which selectively affects a neuronal network outside of the hippocampus might also be missed.

\section{Conclusion}

We identified three electrophysiological parameters in hippocampal slices that could be modified by proconvulsive compounds: the PS 
shape (multiple spikes could appear in the presence of proconvulsive compounds), the CA1 neuron firing rate (it could be increased in the presence of proconvulsive compounds) and the overall hippocampal network synchrony (ED could occur in the presence of proconvulsive compounds). The effect of proconvulsive compounds on these parameters could be reversed by AEDs, thereby confirming their relevance. The evaluation of each compound on all three parameters is crucial since they bring complementary information, and delineate the profile of the compound, i.e. which target might be responsible for its proconvulsive properties.

In the next steps of the platform development, it will be of value to increase the sensitivity of the platform, so that even weak proconvulsive compounds could be detected. The validation of this electrophysiological-based platform (NS-PC set) will also require evaluation of a larger number of seizurogenic or proconvulsive compounds that failed along their development (from Lead to Investigated New Drug stage) as well as negative controls. Finally, it would be optimal to determine the concentration-response of each compound while using a low compound quantity and a low number of animals. This would help to define the predictability of the platform with respect to existing data from in vitro assays as well as in vivo data from animals or humans.

\section{Funding sources}

This research did not receive any specific grant from funding agencies in the public, commercial, or not-for-profit sectors.

\section{References}

Accardi, M. V., Huang, H., \& Authier, S. (2018). Seizure liability assessments using the hippocampal tissue slice: Comparison of non-clinical species. Journal of Pharmacological and Toxicological Methods, 93, 59-68. https://doi.org/10.1016/j. vascn.2017.11.003.

Andersen, P., Bliss, T. V. P., \& Skrede, K. K. (1971). Lamellar organization of hippocampal excitatory pathways. Experimental Brain Research, 13(2), https://doi.org/10.1007/ BF00234087.

Andrade, E. L., Bento, A. F., Cavalli, J., Oliveira, S. K., Schwanke, R. C., Siqueira, J. M., ... Calixto, J. B. (2016). Non-clinical studies in the process of new drug development Part II: Good laboratory practice, metabolism, pharmacokinetics, safety and dose translation to clinical studies. Brazilian Journal of Medical and Biological Research, 49(12), https://doi.org/10.1590/1414-431x20165646.

Authier, S., Arezzo, J., Delatte, M. S., Kallman, M.-J., Markgraf, C., Paquette, D., .. Curtis, M. J. (2016). Safety pharmacology investigations on the nervous system: An industry survey. Journal of Pharmacological and Toxicological Methods, 81, 37-46. https://doi. org/10.1016/j.vascn.2016.06.001.

Avoli, M., Louvel, J., Kurcewicz, I., Pumain, R., \& Barbarosie, M. (1996). Extracellular free potassium and calcium during synchronous activity induced by 4 -aminopyridine in the juvenile rat hippocampus. The Journal of Physiology, 493(3), 707-717. https:// doi.org/10.1113/jphysiol.1996.sp021416.

Avoli, M., D'Antuono, M., Louvel, J., Köhling, R., Biagini, G., Pumain, R., ... Tancredi, V. (2002). Network and pharmacological mechanisms leading to epileptiform synchronization in the limbic system in vitro. Progress in Neurobiology, 68(3), 167-207. https://doi.org/10.1016/S0301-0082(02)00077-1.

Avoli, M., \& de Curtis, M. (2011). GABAergic synchronization in the limbic system and its role in the generation of epileptiform activity. Progress in Neurobiology, 95(2), 104-132. https://doi.org/10.1016/j.pneurobio.2011.07.003.

Bains, J. S., Longacher, J. M., \& Staley, K. J. (1999). Reciprocal interactions between CA3 network activity and strength of recurrent collateral synapses. Nature Neuroscience, 2(8), 720-726. https://doi.org/10.1038/11184.

Bankstahl, M., Bankstahl, J. P., Bloms-Funke, P., \& Löscher, W. (2012). Striking differences in proconvulsant-induced alterations of seizure threshold in two rat models. NeuroToxicology, 33(1), 127-137. https://doi.org/10.1016/j.neuro.2011.12.011.

Ben-Ari, Y., \& Gho, M. (1988). Long-lasting modification of the synaptic properties of rat CA3 hippocampal neurones induced by kainic acid. The Journal of Physiology, 404(1), 365-384. https://doi.org/10.1113/jphysiol.1988.sp017294.

Ben-Ari, Y., \& Cossart, R. (2000). Kainate, a double agent that generates seizures: Two decades of progress. Trends in Neurosciences, 23(11), 580-587. https://doi.org/10. 1016/S0166-2236(00)01659-3.

Bianchi, D., Marasco, A., Limongiello, A., Marchetti, C., Marie, H., Tirozzi, B., \& Migliore, M. (2012). On the mechanisms underlying the depolarization block in the spiking dynamics of CA1 pyramidal neurons. Journal of Computational Neuroscience, 33(2), 207-225. https://doi.org/10.1007/s10827-012-0383-y.

Bradley, J. A., Luithardt, H. H., Metea, M. R., \& Strock, C. J. (2018). In vitro screening for seizure liability using microelectrode Array technology. Toxicological Sciences, 163(1), 240-253. https://doi.org/10.1093/toxsci/kfy029.

Buckle, P. J., \& Haas, H. L. (1982). Enhancement of synaptic transmission by 4-aminopyridine in hippocampal slices of the rat. The Journal of Physiology, 326(1), 109-122. https://doi.org/10.1113/jphysiol.1982.sp014180.

Cataldi, M., Panuccio, G., Cavaccini, A., D'Antuono, M., Taglialatela, M., \& Avoli, M. (2011). Involvement of inward rectifier and M-type currents in carbachol-induced epileptiform synchronization. Neuropharmacology, 60(4), 653-661. https://doi.org/ 10.1016/j.neuropharm.2010.11.023.

Chen, H.-Y., Albertson, T. E., \& Olson, K. R. (2016). Treatment of drug-induced seizures. British Journal of Clinical Pharmacology, 81(3), 412-419. https://doi.org/10.1111/ bcp. 12720 .

Chesi, A. J. R., \& Stone, T. W. (1997). Alkylxanthine adenosine antagonists and epileptiform activity in rat hippocampal slices in vitro. Experimental Brain Research, 113(2), 303-310. https://doi.org/10.1007/BF02450328.

Cohen, S. L., Morley, B. J., \& Snead, O. C. (1981). An EEG analysis of convulsive activity produced by cholinergic agents. Progress in Neuro-Psychopharmacology, 5(4), 383-388.

Cole, A., \& Nicoll, R. (1983). Acetylcholine mediates a slow synaptic potential in hippocampal pyramidal cells. Science, 221(4617), 1299-1301. https://doi.org/10.1126/ science.6612345.

Cole, A. E., \& Nicoll, R. A. (1984). The pharmacology of cholinergic excitatory responses in hippocampal pyramidal cells. Brain Research, 305(2), 283-290. https://doi.org/10. 1016/0006-8993(84)90434-7.

Colom, L. V., \& Saggau, P. (1994). Spontaneous interictal-like activity originates in multiple areas of the CA2-CA3 region of hippocampal slices. Journal of Neurophysiology, 71(4), 1574-1585. https://doi.org/10.1152/jn.1994.71.4.1574.

Cruickshank, J. W., Brudzynski, S. M., \& McLachlan, R. S. (1994). Involvement of M1 muscarinic receptors in the initiation of cholinergically induced epileptic seizures in the rat brain. Brain Research, 643(1-2), 125-129. https://doi.org/10.1016/00068993(94)90017-5.

Debanne, D., Thompson, S. M., \& Gahwiler, B. H. (2006). A brief period of Epileptiform activity strengthens excitatory synapses in the rat Hippocampus in vitro. Epilepsia, 47(2), 247-256. https://doi.org/10.1111/j.1528-1167.2006.00416.x.

DiMasi, J. A., Grabowski, H. G., \& Hansen, R. W. (2016). Innovation in the pharmaceutical industry: New estimates of R\&D costs. Journal of Health Economics, 47, 20-33. https://doi.org/10.1016/j.jhealeco.2016.01.012.

Durand, D. M., Park, E.-H., \& Jensen, A. L. (2010). Potassium diffusive coupling in neural networks. Philosophical Transactions of the Royal Society B: Biological Sciences, 365(1551), 2347-2362. https://doi.org/10.1098/rstb.2010.0050.

Dürmüller, N., Guillaume, P., Lacroix, P., Porsolt, R. D., \& Moser, P. (2007). The use of the dog electroencephalogram (EEG) in safety pharmacology to evaluate proconvulsant risk. Journal of Pharmacological and Toxicological Methods, 56(2), 234-238. https:// doi.org/10.1016/j.vascn.2007.03.006.

Easter, A., Sharp, T. H., Valentin, J.-P., \& Pollard, C. E. (2007). Pharmacological validation of a semi-automated in vitro hippocampal brain slice assay for assessment of seizure liability. Journal of Pharmacological and Toxicological Methods, 56(2), 223-233. https://doi.org/10.1016/j.vascn.2007.04.008.

Easter, A., Bell, M. E., Damewood, J. R., Redfern, W. S., Valentin, J.-P., Winter, M. J., .. Bialecki, R. A. (2009). Approaches to seizure risk assessment in preclinical drug discovery. Drug Discovery Today, 14(17-18), 876-884. https://doi.org/10.1016/j. drudis.2009.06.003.

FDA (2017). Assessment of abuse potential of drugs guidance for industry. 37.

Federico, P., \& MacVicar, B. A. (1996). Imaging the induction and spread of seizure activity in the isolated brain of the Guinea pig: The roles of GABA and glutamate receptors. Journal of Neurophysiology, 76(5), 3471-3492. https://doi.org/10.1152/jn. 1996.76.5.3471.

de Feo, M. R., Mecarelli, O., \& Ricci, G. F. (1985). Bicuculline- and allylglycine-induced epilepsy in developing rats. Experimental Neurology, 90(2), 411-421. https://doi.org/ 10.1016/0014-4886(85)90030-5.

Fisher, R. S., \& Alger, B. E. (1984). Electrophysiological mechanisms of kainic acid-induced epileptiform activity in the rat hippocampal slice. The Journal of Neuroscience: The Official Journal of the Society for Neuroscience, 4(5), 1312-1323. https://doi.org/ 10.1523/JNEUROSCI.04-05-01312.1984.

Fraser, D. D., \& MacVicar, B. A. (1996). Cholinergic-dependent plateau potential in hippocampal CA1 pyramidal neurons. The Journal of Neuroscience, 16(13), 4113-4128. https://doi.org/10.1523/JNEUROSCI.16-13-04113.1996.

Froemke, R. C. (2010). Temporal modulation of spike-timing-dependent plasticity. Frontiers in Synaptic Neuroscience.. https://doi.org/10.3389/fnsyn.2010.00019.

Gonzalez-Sulser, A., Wang, J., Motamedi, G. K., Avoli, M., Vicini, S., \& Dzakpasu, R. (2011). The 4-aminopyridine in vitro epilepsy model analyzed with a perforated multi-electrode array. Neuropharmacology, 60(7-8), 1142-1153. https://doi.org/10. 1016/j.neuropharm.2010.10.007.

Hamdam, J., Sethu, S., Smith, T., Alfirevic, A., Alhaidari, M., Atkinson, J., ... Goldring, C. (2013). Safety pharmacology - Current and emerging concepts. Toxicology and Applied Pharmacology, 273(2), 229-241. https://doi.org/10.1016/j.taap.2013.04. 039.

Hasselmo, M., \& Schnell, E. (1994). Laminar selectivity of the cholinergic suppression of synaptic transmission in rat hippocampal region CA1: Computational modeling and brain slice physiology. The Journal of Neuroscience, 14(6), 3898-3914. https://doi. org/10.1523/JNEUROSCI.14-06-03898.1994.

Irwin, S. (1968). Comprehensive observational assessment: Ia. A systematic, quantitative procedure for assessing the behavioral and physiologic state of the mouse. Psychopharmacologia, 13(3), 222-257.

Johnston, D., \& Brown, T. H. (1981). Giant synaptic potential hypothesis for epileptiform activity. Science (New York, N.Y.), 211(4479), 294-297.

Kaitin, K. I. (2010). Deconstructing the drug development process: The new face of innovation. Clinical Pharmacology \& Therapeutics, 87(3), 356-361. https://doi.org/10. 1038/clpt.2009.293.

Kitano, Y., Usui, C., Takasuna, K., Hirohashi, M., \& Nomura, M. (1996). Increasing- 
current electroshock seizure test: A new method for assessment of anti- and proconvulsant activities of drugs in mice. Journal of Pharmacological and Toxicological Methods, 35(1), 25-29. https://doi.org/10.1016/1056-8719(95)00115-8.

Klausberger, T. (2009). GABAergic interneurons targeting dendrites of pyramidal cells in the CA1 area of the hippocampus. European Journal of Neuroscience, 30(6), 947-957. https://doi.org/10.1111/j.1460-9568.2009.06913.x.

Kola, I., \& Landis, J. (2004). Can the pharmaceutical industry reduce attrition rates? Nature reviews. Drug Discovery, 3(8), 1474-1776. https://doi.org/10.1038/nrd1470.

Lees, G. J., \& Sandberg, M. (1991). Evoked field potential changes in the rat hippocampus produced by toxic doses of glutamate agonists and metabolic inhibitors: Correlation with subsequent neuronal death. Experimental Brain Research, 85(3), https://doi.org/ 10.1007/BF00231748.

Lévesque, M., \& Avoli, M. (2013). The kainic acid model of temporal lobe epilepsy. Neuroscience \& Biobehavioral Reviews, 37(10), 2887-2899. https://doi.org/10.1016/j. neubiorev.2013.10.011.

Lévesque, M., Cataldi, M., Chen, L.-Y., Hamidi, S., \& Avoli, M. (2017). Carbachol-induced network oscillations in an in vitro limbic system brain slice. Neuroscience, 348 , 153-164. https://doi.org/10.1016/j.neuroscience.2017.02.021.

Lipski, J., Bellingham, M. C., West, M. J., \& Pilowsky, P. (1988). Limitations of the technique of pressure microinjection of excitatory amino acids for evoking responses from localized regions of the CNS. Journal of Neuroscience Methods, 26(2), 169-179. https://doi.org/10.1016/0165-0270(88)90166-5.

Löscher, W. (2009). Preclinical assessment of proconvulsant drug activity and its relevance for predicting adverse events in humans. European Journal of Pharmacology, 610(1-3), 1-11. https://doi.org/10.1016/j.ejphar.2009.03.025.

Löscher, W., Hönack, D., Fassbender, C. P., \& Nolting, B. (1991). The role of technical, biological and pharmacological factors in the laboratory evaluation of anticonvulsant drugs. III. Pentylenetetrazole seizure models. Epilepsy Research, 8(3), 171-189. https://doi.org/10.1016/0920-1211(91)90062-K.

Löscher, W., \& Schmidt, D. (1988). Which animal models should be used in the search for new antiepileptic drugs? A proposal based on experimental and clinical considerations. Epilepsy Research, 2(3), 145-181. https://doi.org/10.1016/0920-1211(88) 90054-X.

Lothman, E. W. (1994). Seizure circuits in the hippocampus and associated structures. Hippocampus, 4(3), 286-290. https://doi.org/10.1002/hipo.450040311.

Lux, H. D., Heinemann, U., \& Dietzel, I. (1986). Ionic changes and alterations in the size of the extracellular space during epileptic activity. Advances in Neurology, 44, 619-639.

Mead, A. N., Amouzadeh, H. R., Chapman, K., Ewart, L., Giarola, A., Jackson, S. J., ... Vargas, H. M. (2016). Assessing the predictive value of the rodent neurofunctional assessment for commonly reported adverse events in phase I clinical trials. Regulatory Toxicology and Pharmacology, 80, 348-357. https://doi.org/10.1016/j.yrtph.2016.05. 002.

Menendez de la Prida, L., Huberfeld, G., Cohen, I., \& Miles, R. (2006). Threshold behavior in the initiation of hippocampal population bursts. Neuron, 49(1), 131-142. https:// doi.org/10.1016/j.neuron.2005.10.034.

Mitterdorfer, J., \& Bean, B. P. (2002). Potassium currents during the action potential of hippocampal CA3 neurons. The Journal of Neuroscience: The Official Journal of the Society for Neuroscience, 22(23), 10106-10115.

Moser, V. C., Cheek, B. M., \& MacPhail, R. C. (1995). A multidisciplinary approach to toxicological screening: III. Neurobehavioral toxicity. Journal of Toxicology and Environmental Health, 45(2), 173-210. https://doi.org/10.1080/ 15287399509531988.

McQuiston, A. R. (2010). Cholinergic modulation of excitatory synaptic input integration in hippocampal CA1: Acetylcholine and excitatory synaptic integration in hippocampal CA1. The Journal of Physiology, 588(19), 3727-3742. https://doi.org/10. 1113/jphysiol.2010.188581.

Perreault, P., \& Avoli, M. (1991). Physiology and pharmacology of epileptiform activity induced by 4-aminopyridine in rat hippocampal slices. Journal of Neurophysiology, 65(4), 771-785. https://doi.org/10.1152/jn.1991.65.4.771.

Pillai, J., \& Sperling, M. R. (2006). Interictal EEG and the diagnosis of epilepsy. Epilepsia, 47(s1), 14-22. https://doi.org/10.1111/j.1528-1167.2006.00654.x.

Rama, S., Zbili, M., Fékété, A., Tapia, M., Benitez, M. J., Boumedine, N., ... Debanne, D. (2017). The role of axonal Kv1 channels in CA3 pyramidal cell excitability. Scientific Reports, 7(1), https://doi.org/10.1038/s41598-017-00388-1.
Rogawski, M. A., Löscher, W., \& Rho, J. M. (2016). Mechanisms of action of antiseizure drugs and the ketogenic diet. Cold Spring Harbor Perspectives in Medicine, 6(5), a022780. https://doi.org/10.1101/cshperspect.a022780.

Rowan, M. J. (1984). Central nervous system toxicity evaluation in vitro: neurophysiological approach. Neurotoxicolgy (Drug and Chemical Toxicology) (Marcel Dekker). 3. Neurotoxicolgy (Drug and Chemical Toxicology) (Marcel Dekker) (pp. 586-612). New York: K. Blum and L. Manzo.

Rutecki, P. A., Lebeda, F. J., \& Johnston, D. (1987). 4-Aminopyridine produces epileptiform activity in hippocampus and enhances synaptic excitation and inhibition. Journal of Neurophysiology, 57(6), 1911-1924. https://doi.org/10.1152/jn.1987.57. 6.1911.

Schwartzkroin, P. A. (1994). Role of the hippocampus in epilepsy. Hippocampus, 4(3), 239-242. https://doi.org/10.1002/hipo.450040302.

Semyanov, A., \& Godukhin, O. (2001). Epileptiform activity and EPSP-spike potentiation induced in rat hippocampal CA1 slices by repeated high- $\mathrm{K}+:$ Involvement of ionotropic glutamate receptors and $\mathrm{Ca} 2+/$ calmodulin-dependent protein kinase II. Neuropharmacology, 40(2), 203-211. https://doi.org/10.1016/S0028-3908(00) 00147-7.

Semyanov, A., Morenkov, E., Savin, A., \& Godukhin, O. (1999). In vivo hippocampal kindling occludes the development of in vitro kindling-like state in CA1 area of rat hippocampal slices. Epilepsy Research, 38(1), 75-85. https://doi.org/10.1016/S09201211(99)00076-5.

Spyker, D. A., Lynch, C., Shabanowitz, J., \& Sinn, J. A. (1980). Poisoning with 4-aminopyridine: Report of three cases. Clinical Toxicology, 16(4), 487-497. https://doi. org/10.3109/15563658008989978.

Staley, K. J., White, A., \& Dudek, F. E. (2011). Interictal spikes: Harbingers or causes of epilepsy? Neuroscience Letters, 497(3), 247-250. https://doi.org/10.1016/j.neulet 2011.03.070.

Swann, J. W., \& Gomez-Di Cesare, C. M. (1994). Developmental plasticity and hippocampal epileptogenesis. Hippocampus, 4(3), 266-269. https://doi.org/10.1002/hipo. 450040307.

Tancredi, V., \& Avoli, M. (1987). Control of spontaneous epileptiform discharges by extracellular potassium: An in vitro study in the CA1 subfield of the hippocampal slice. Experimental Brain Research, 67(2), https://doi.org/10.1007/BF00248556.

Tasker, R. A. R., Bernard, P. B., Doucette, T. A., Kerr, D. S., Zabidin, Y., AlvarezFernandez, L., ... Novelli, A. (2002). Comparison of the in vitro and in vivo neurotoxicity of three new sources of kainic acid. Amino Acids, 23(1-3), 45-54. https://doi. org/10.1007/s00726-001-0108-4.

Thesleff, S. (1980). Aminopyridines and synaptic transmission. Neuroscience, 5(8), 1413-1419.

Traub, R. D., \& Wong, R. K. S. (1981). Penicillin-induced epileptiform activity in the hippocampal slice: A model of synchronization of CA3 pyramidal cell bursting. Neuroscience, 6(2), 223-230. https://doi.org/10.1016/0306-4522(81)90058-0.

Traub, R. D., \& Jefferys, J. G. R. (1994). Simulations of epileptiform activity in the hippocampal CA3 region in vitro. Hippocampus, 4(3), 281-285. https://doi.org/10. 1002/hipo.450040310.

Blum, Manzo, L., Valentino, R., \& Dingledine, R. (1981). Presynaptic inhibitory effect of acetylcholine in the hippocampus. The Journal of Neuroscience, 1(7), 784-792.

Vargas, J. R., Takahashi, D. K., Thomson, K. E., \& Wilcox, K. S. (2013). The Expression of Kainate Receptor Subunits in Hippocampal Astrocytes After Experimentally Induced Status Epilepticus. Journal of Neuropathology \& Experimental Neurology, 72(10), 919-932. https://doi.org/10.1097/NEN.0b013e3182a4b266.

Williams, J. H., \& Kauer, J. A. (1997). Properties of carbachol-induced oscillatory activity in rat hippocampus. Journal of Neurophysiology, 78(5), 2631-2640. https://doi.org/ 10.1152/jn.1997.78.5.2631.

Winter, M. J., Redfern, W. S., Hayfield, A. J., Owen, S. F., Valentin, J.-P., \& Hutchinson, T. H. (2008). Validation of a larval zebrafish locomotor assay for assessing the seizure liability of early-stage development drugs. Journal of Pharmacological and Toxicological Methods, 57(3), 176-187. https://doi.org/10.1016/j.vascn.2008.01. 004.

Zhang, H., Li, W., Xie, Y., Wang, W.-J., Li, L.-L., \& Yang, S.-Y. (2011). Rapid and accurate assessment of seizure liability of drugs by using an optimal support vector machine method. Toxicology In Vitro, 25(8), 1848-1854. https://doi.org/10.1016/j.tiv.2011. 05.015 . 